\title{
Report on FY19 Testing in Support of Grade 91 Core Block Code Case
}

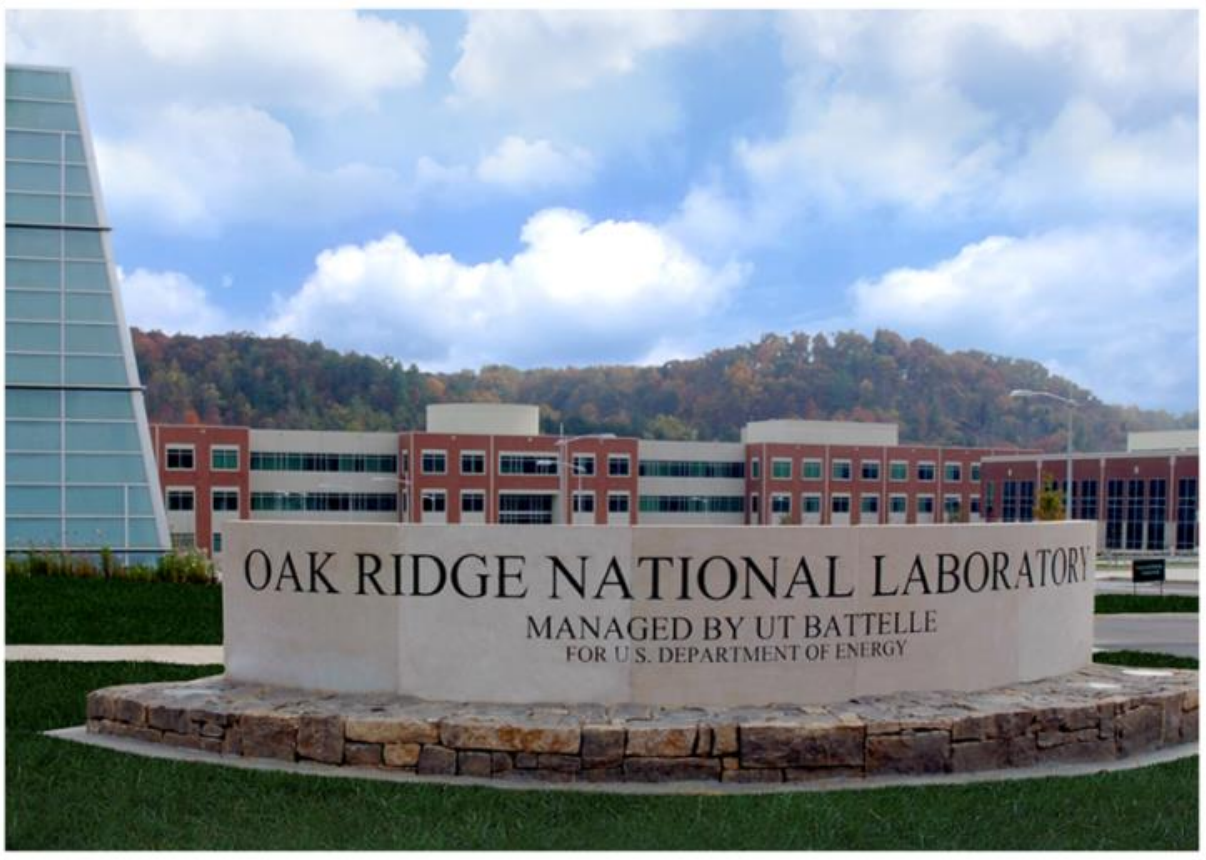

Yanli Wang Robert I. Jetter Mark C. Messner T.-L. Sham

September 2019

Approved for public release. Distribution is unlimited. 


\title{
DOCUMENT AVAILABILITY
}

Reports produced after January 1, 1996, are generally available free via US Department of Energy (DOE) SciTech Connect.

Website www.osti.gov

Reports produced before January 1, 1996, may be purchased by members of the public from the following source:

\author{
National Technical Information Service \\ 5285 Port Royal Road \\ Springfield, VA 22161 \\ Telephone 703-605-6000 (1-800-553-6847) \\ TDD 703-487-4639 \\ Fax 703-605-6900 \\ E-mail info@ntis.gov \\ Website http://classic.ntis.gov/
}

Reports are available to DOE employees, DOE contractors, Energy Technology Data Exchange representatives, and International Nuclear Information System representatives from the following source:

Office of Scientific and Technical Information

PO Box 62

Oak Ridge, TN 37831

Telephone 865-576-8401

Fax 865-576-5728

E-mail reports@osti.gov

Website http://www.osti.gov/contact.html

This report was prepared as an account of work sponsored by an agency of the United States Government. Neither the United States Government nor any agency thereof, nor any of their employees, makes any warranty, express or implied, or assumes any legal liability or responsibility for the accuracy, completeness, or usefulness of any information, apparatus, product, or process disclosed, or represents that its use would not infringe privately owned rights. Reference herein to any specific commercial product, process, or service by trade name, trademark, manufacturer, or otherwise, does not necessarily constitute or imply its endorsement, recommendation, or favoring by the United States Government or any agency thereof. The views and opinions of authors expressed herein do not necessarily state or reflect those of the United States Government or any agency thereof. 


\title{
REPORT ON FY19 TESTING IN SUPPORT OF GRADE 91 CORE BLOCK CODE CASE
}

\author{
Yanli Wang \\ Robert I. Jetter* \\ Mark C. Messner ${ }^{\dagger}$ \\ T.-L. Sham ${ }^{\dagger}$
}

\footnotetext{
* RI Jetter Consulting

$\uparrow$ Argonne National Laboratory
}

\author{
Prepared by \\ OAK RIDGE NATIONAL LABORATORY \\ Oak Ridge, TN 37831-6283 \\ managed by \\ UT-BATTELLE, LLC \\ for the \\ US DEPARTMENT OF ENERGY \\ under contract DE-AC05-00OR22725
}





\section{CONTENTS}

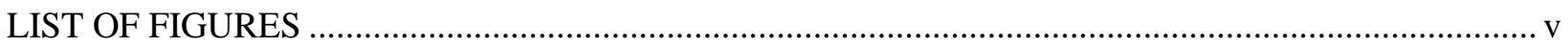

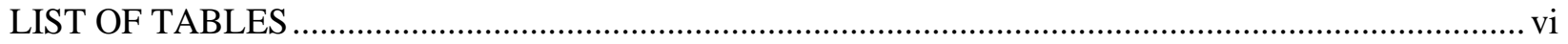

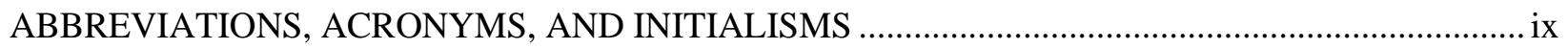

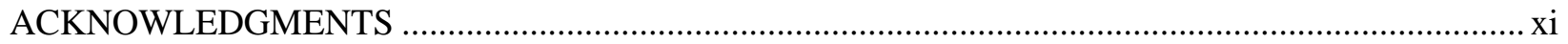

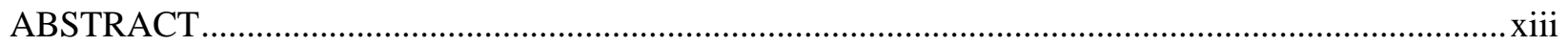

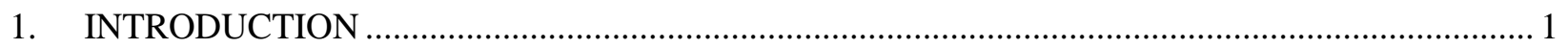

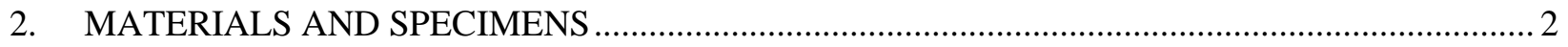

3. EFFECT OF MEAN STRESS ON THE FATIGUE DESIGN CURVES OF GR. 91 .................... 2

3.1 STRAIN-CONTROLLED MEAN STRESS TESTING PROCEDURE ................................ 3

3.2 EVALUATION OF MEAN STRESS EFFECT ON THE FATIGUE DESIGN CURVES

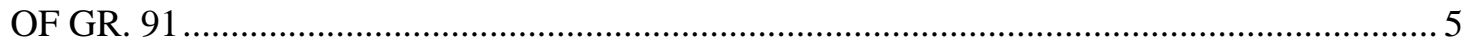

4. TESTING IN SUPPORT OF EXTENSION OF THE EPP STRAIN LIMITS CODE CASE TO GR. 91 .

5. PROGRESS IN DEVELOPMENT OF ALTERNATIVE CREEP-FATIGUE EVALUATION METHOD FOR GR. 91

5.1 DEVELOPMENT OF INTEGRATED EPP-SMT CF EVALUATION METHODOLOGY .

5.2 SMT CREEP-FATIGUE TESTING ON GR. 91.

5.3 TBSMT CREEP-FATIGUE ON GR. 91 WITH A ROOM-TEMPERATURE DRIVER BAR 13

5.4 TBSMT CREEP-FATIGUE ON GR. 91 WITH A CREEPING DRIVER BAR …................. 17

5.5 SBSMT TEST RESULTS ON GR. 91 18

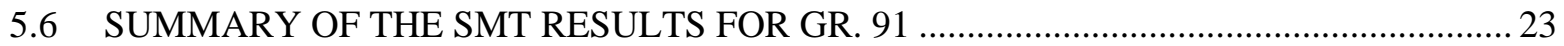

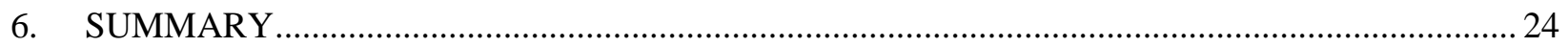

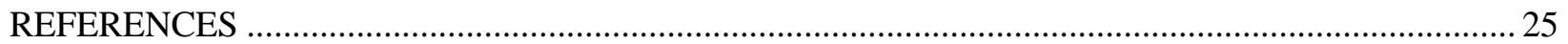





\section{LIST OF FIGURES}

Fig. 1. Standard CF specimen geometry. Units are in millimeter..................................................... 2

Fig. 2. Schematics of strain-controlled fatigue testing with zero initial mean stress (a) and with

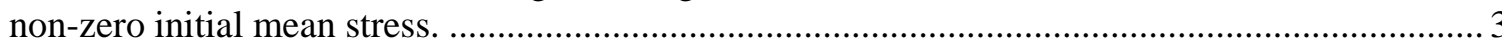

Fig. 3. Tensile stress-strain curves of Gr. 91 (heat 30176) at $540^{\circ} \mathrm{C}$ and $371^{\circ} \mathrm{C}$ and strain rate of

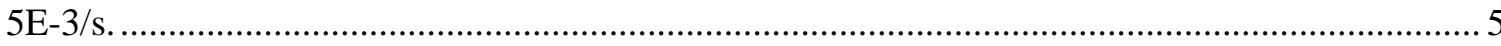

Fig. 4. Comparison of the stress ranges for strain-controlled fatigue tests with and without initial

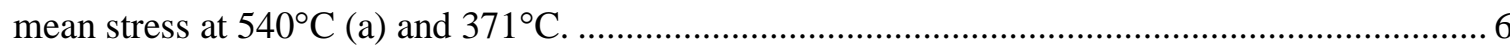

Fig. 5. Comparison of the strain-controlled mean strain fatigue test results with the JSME best fit

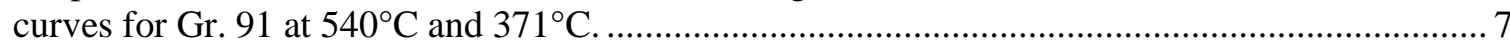

Fig. 6. Representative hysteresis loops of strain-controlled fatigue tests at $540^{\circ} \mathrm{C}$ for $\mathrm{Gr} .91$ (heat 30176). (a) with non-zero initial mean stress and (b) with zero initial mean stress........................ 7

Fig. 7. Representative hysteresis loops of strain-controlled fatigue tests at $371^{\circ} \mathrm{C}$ for $\mathrm{Gr} .91$ (heat 30176). (a) with non-zero initial mean stress and (b) with zero initial mean stress........................ 8

Fig. 8. Measured mean stresses as a function of loading cycles for mean strain effect testing at $540^{\circ} \mathrm{C}$ with applied cycles in logarithmic scale (a) and linear scale (b).................................... 9

Fig. 9. Measured mean stresses as a function of loading cycles for mean strain effect testing at $371^{\circ} \mathrm{C}$ with the applied cycles in logarithmic scale (a) and linear scale (b) . ............................... 9

Fig. 10. Schematics of the experiment to evaluate the cyclic softening effect for Gr. 91 ...................... 10

Fig. 11. Effect of cyclic softening on creep rate of Gr. 91 (heat 30176 ) at $600^{\circ} \mathrm{C}(\mathrm{a}), 625^{\circ} \mathrm{C}(\mathrm{b})$,

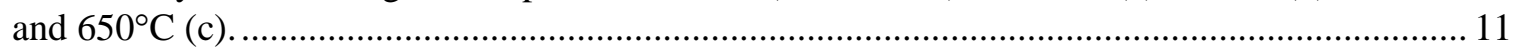

Fig. 12. Effect of cyclic softening on creep behavior of Gr. 91 (heat 30176). ....................................... 12

Fig. 13. Applied CF loading profiles for one cycle with compression hold. Starting with compression holding segment (a) or the tension loading segment (b) ....................................... 13

Fig. 14. Stress-strain curves of the room-temperature driver bar for TB03 ............................................ 14

Fig. 15. Plots of the strain ranges (a), maximum/minimum stresses (b), and stress history of the first five cycles (c) and the representative hysteresis loops (d) for TB03 at $650^{\circ} \mathrm{C} \ldots \ldots \ldots \ldots \ldots \ldots \ldots . . . . . . . .15$

Fig. 16. Normalized strain range, stress range, and stress relaxation ratio for TB03............................. 15

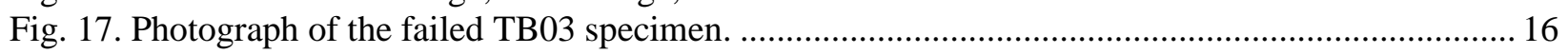

Fig. 18. Plots of the strain ranges (a), maximum/minimum stresses (b), and hysteresis loops of

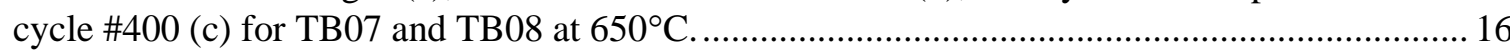

Fig. 19. Plots of the strain ranges (a), maximum/minimum strains (b), maximum/minimum

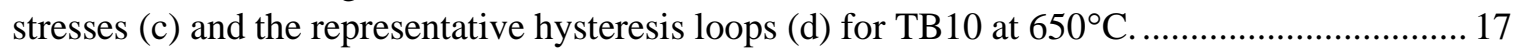

Fig. 20. Details of the stress relaxation during hold segment of cycle \#200 for TB10.......................... 18

Fig. 21. Plots of the strain ranges (a), maximum/minimum stresses (b), and representative hysteresis loops (c) for $\mathrm{SB} 05$ at $650^{\circ} \mathrm{C}$.

Fig. 22. Comparison of the maximum and minimum stresses (a) and hysteresis loops of cycle \# 200 (b) for SB05 and TB07.

Fig. 23. Plots of the maximum/minimum stresses (a), maximum/minimum strains (b), strain ranges (c), stress ranges (d) for SB09 and SB10, and representative hysteresis loops for SB09 (e) and SB10 (f)...

Fig. 24. Plots of the strain ranges (a), maximum/minimum stresses (b), maximum/minimum strains (c), stress ranges (d), stress history of the first five cycles (e) and representative

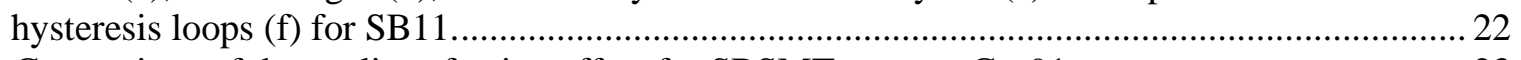

Fig. 25. Comparison of the cyclic softening effect for SBSMT tests on Gr. 91 ..................................... 23

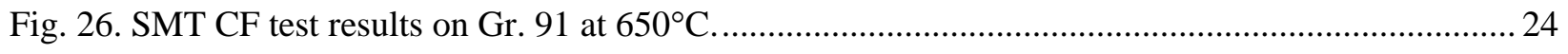




\section{LIST OF TABLES}

Table 1. Chemical compositions of Gr. 91 plate with heat number 30176 (weight \%),.......................... 2

Table 2. Testing parameters for strain-controlled mean stress evaluation on fatigue life of Gr. 91 (heat 30176 ) at $540^{\circ} \mathrm{C}$ and $371^{\circ} \mathrm{C}$.

Table 3. Summary of the test results of strain-controlled mean stress evaluation on Gr. 91 (heat 30176) at $540^{\circ} \mathrm{C}$ and $371^{\circ} \mathrm{C}$.

Table 4. Summary of the test parameters of the cyclic softening effect on the creep rate of Gr. 91 (heat 30176).

Table 5. Summary of SMT CF results on Gr. 91 at $650^{\circ} \mathrm{C}$ (heat 30176). 


\section{ABBREVIATIONS, ACRONYMS, AND INITIALISMS}

$\begin{array}{ll}\text { ART } & \text { Advanced Reactor Technologies } \\ \text { ANL } & \text { Argonne National Laboratory } \\ \text { ASME } & \text { American Society of Mechanical Engineers } \\ \text { B\&PV } & \text { Boiler and Pressure Vessel } \\ \text { CF } & \text { Creep-Fatigue } \\ \text { DOE } & \text { Department of Energy } \\ \text { EPP } & \text { elastic-perfectly plastic } \\ \text { Gr. 91 } & \text { modified Grade 91 Steel (9Cr-1Mo-V Steel) } \\ \text { ISSC } & \text { isochronous stress-strain curve } \\ \text { ORNL } & \text { Oak Ridge National Laboratory } \\ \text { SMT } & \text { Simplified Model Test } \\ \text { TBSMT } & \text { two-bar SMT } \\ \text { SBSMT } & \text { single-bar SMT }\end{array}$




\section{ACKNOWLEDGMENTS}

This research was sponsored by the US Department of Energy (DOE), Office of Nuclear Energy (NE), under contract No. DE-AC02-06CH1 1357 with Argonne National Laboratory, managed and operated by UChicago Argonne LLC, and under contract DE-AC05-00OR22725 with Oak Ridge National Laboratory (ORNL), managed and operated by UT-Battelle LLC. Programmatic direction was provided by the Office of Nuclear Reactor Deployment of DOE NE.

The authors gratefully acknowledge the support provided by Tom Sowinski, DOE-NE, Federal Manager, Microreactors Campaign, Advanced Reactor Technologies (ART) Program; Sue Lesica, DOE-NE, Federal Manager, Advanced Materials, ART Program; and Jess Gehin, Idaho National Laboratory, National Technical Director, Microreactors Campaign, ART Program.

The authors also wish to thank ORNL staff members C. Shane Hawkins for technical support and Donald Erdman III and Zhili Feng for reviewing this report. 


\begin{abstract}
This report summarizes the experimental results performed in FY 2019 on grade 91 (Gr. 91) steel (heat 30176) in support of Gr. 91 core block code cases. Mean stress fatigue testing was completed, and the evaluation led to the conclusion that mean stress correction on the fatigue curve in Division 5 for Gr. 91 is not recommended. A specialized test was designed and performed to validate the methodology proposed for a softening factor to support the extension of the elastic - perfectly plastic (EPP) strain limits design rules to Gr. 91. Nine simplified model tests (SMTs) were completed using the newly developed two-bar SMT (TBSMT) and single-bar SMT (SBSMT) techniques. The results demonstrate the validity of the testing technique, and the experimental basis of the development of the integrated EPP plus SMT creepfatigue evaluation methodology.

This report fulfils the milestone M3AT-19OR050401061, "Complete Planned FY19 Testing in Support of Grade 91 Core Block Code Case."
\end{abstract}





\section{INTRODUCTION}

Grade 91 (Gr. 91) steel is currently an approved material for Class A construction in ASME Section III Division 5, Subsection HB, Subpart B. To support the Microreactors Campaign, integrated research and development activities by Argonne National Laboratory (Argonne) and Oak Ridge National Laboratory (ORNL) are conducted to develop and expand design rules to enable the use of Gr. 91 as a Class A construction material for core block design. In FY 2019, research on Gr. 91 at ORNL mainly involved experiments in support of the incorporation of the temperature-dependent ASME fatigue design curves, extension of the elastic perfectly plastic (EPP) design rules to Gr. 91, and development of an alternative creep-fatigue $(\mathrm{CF})$ design methodology.

The current ASME Boiler and Pressure Vessel (B\&PV) Code Section III, Division 5, Subsection HB, Subpart B has only one design fatigue curve for Gr. 91 at $540^{\circ} \mathrm{C}$ (or $1000^{\circ} \mathrm{F}$ ). The ASME Section III Working Group-Creep-Fatigue and Negligible Creep (WG-CFNC) has taken action to incorporate the temperature-dependent fatigue curves for Gr. 91 in Division 5. During the process, one issue regarding the effect of mean stress effects on fatigue analysis, and how to consider the mean stress effect for elevated-temperature design, was brought up and discussed. To evaluate whether the design fatigue curves of Gr. 91 needed adjustment to account for mean stress, critical tests were designed and performed at ORNL. The experimental results and analysis will be used to finalize the temperature design curves for Gr. 91.

Qualification of Grade 91 steel for EPP strain limits and CF evaluations is a high-priority research and development item of the ASME Code committee responsible for Division 5. The qualification of the EPP methods for Gr. 91 steel has technical significance because currently this steel is the only approved material for Division 5 Class A construction that is strongly cyclic softening. Experimental and modeling research is needed in extending the code cases to Gr. 91 for EPP analysis. A specialized experiment was designed and performed at ORNL to verify the method of determining the effect of the cyclic softening factor in support of extending the EPP methodology to Gr. 91.

The current ASME code rules for CF evaluation based on the damage diagram require the separate evaluation of creep damage and fatigue damage. The uncertainties in the separate evaluation of creep damage and fatigue damage from the test data lead to the use of overly conservative design factors in the current $\mathrm{CF}$ procedure. The difficulty in the current damage diagram $\mathrm{CF}$ evaluation approach has led to the development of an alternative CF evaluation methodology, i.e., the integrated EPP analysis and SMT design methodology. The goal of this integrated EPP-SMT methodology is to maximize the advantages of both EPP methods and the SMT CF evaluation approach. The development of an SMT-based design curve requires a significant amount of SMT test data. Experimentally, SMT key feature CF testing has been successfully developed and tested for Alloy 617, SS 316H, SS 304H, and Gr. 91 (Wang et al. 2013, 2014, 2015, 2016a, 2016b, 2017a, 2017b). However, testing with the key feature SMT specimens has challenges in that it requires specialized and costly instrumentation; and it is difficult to extract information to support the modeling and analysis. Major effort was invested in FY 2018 in developing improved testing techniques to allow easier SMT-based CF testing. The newly improved techniques enable the use of standard CF specimens and significantly simplify the testing program. The new techniques were successfully verified on Alloy 617 and SS 316H in Wang et al.2018a, 2018b, 2019a, 2019b. In FY 2019, experiments were designed and performed using the new SMT testing techniques to support the extension of the integrated EPP-SMT design method to Gr. 91. 


\section{MATERIALS AND SPECIMENS}

The Gr. 91 material used in this report was from the Gr. 91 plate with heat number 30176. It was manufactured by Carpenter Technology Corporation in the early 1980s, and it has been preserved at ORNL as an archival material. ORNL technical report ORNL-6303 documented the chemical composition of this plate, which is listed in Table 1 below. Note that the silicon content is $0.11 \%$, lower than the ASME SA-387 specification of $0.2-0.5 \%$. This plate was characterized for its mechanical properties and the data were used as reference data for the Gr. 91 development program.

Table 1. Chemical compositions of Gr. 91 plate with heat number 30176 (weight \%).

\begin{tabular}{c|c|c|c|c|c|c|c|c|c|c}
\hline $\mathbf{C}$ & $\mathbf{P}$ & $\mathbf{S i}$ & $\mathbf{N i}$ & $\mathbf{M n}$ & $\mathbf{N}$ & $\mathbf{T i}$ & $\mathbf{S n}$ & $\mathbf{V}$ & $\mathbf{F e}$ & $\mathbf{A s}$ \\
\hline 0.081 & 0.010 & 0.11 & 0.09 & 0.37 & 0.055 & 0.004 & $<0.001$ & 0.209 & balance & 0.001 \\
\hline $\mathbf{Z r}$ & $\mathbf{S}$ & $\mathbf{C r}$ & $\mathbf{C o}$ & $\mathbf{M o}$ & $\mathbf{A l}$ & $\mathbf{W}$ & $\mathbf{C u}$ & $\mathbf{N b}$ & $\mathbf{B}$ & \\
\hline$<0.001$ & 0.003 & 8.61 & 0.010 & 0.89 & 0.007 & $<0.01$ & 0.04 & 0.072 & $<\mathbf{0 . 0 9}$ & \\
\hline
\end{tabular}

*Note: heat 30176 is low in Si content.

The as-received Gr. 91 plate was hot forged followed by hot rolling. The nominal thickness of the plate was $25.4 \mathrm{~mm}$ (or $1 \mathrm{in}$.). The plate material was heat treated to support this study. It was normalized at $1050^{\circ} \mathrm{C}$ for $1 \mathrm{~h}$ and then tempered at $76^{\circ} \mathrm{C}$ for $2 \mathrm{~h}$, followed by air cooling. The heat treatment was performed by Bodycote Thermal Processing Inc. in Morristown, Tennessee. The heat-treated Gr. 91 satisfied ASME specification SA-387.

All the specimens used in this study were machined along the plate rolling direction. The specimen geometries used in the report are the same as those used in previously by Wang et al. (2017a).

The standard CF specimen has a $6.35 \mathrm{~mm}$ (0.25 in.) gage diameter, as shown in Fig. 1.

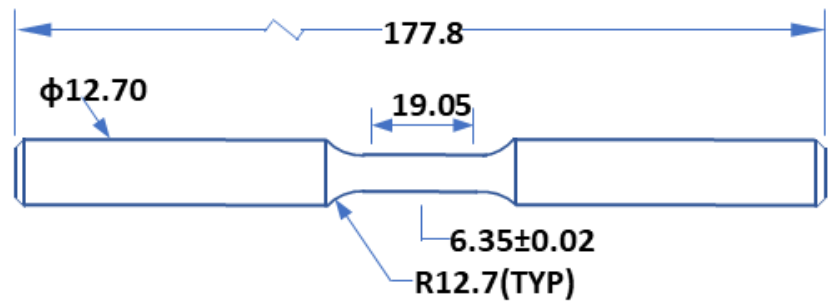

Fig. 1. Standard CF specimen geometry. Units are in millimeter.

\section{EFFECT OF MEAN STRESS ON THE FATIGUE DESIGN CURVES OF GR. 91}

The current ASME B\&PV Code Section III Division 5, Subsection HB, Subpart B has only one design fatigue curve for Gr. 91 at $540^{\circ} \mathrm{C}$ (or $1000^{\circ} \mathrm{F}$ ). The ASME Section III WG-CFNC has taken action and established the record number 15-2731 to incorporate the Japan Society of Mechanical Engineers (JSME) temperature-dependent fatigue curves for Gr. 91 in Division 5. The temperature-dependent fatigue curves in the JSME Codes for Nuclear Power Generation Facilities-Rules on Design and Construction for Nuclear Power Plants were established in 2012 and are considered the most reliable temperaturedependent fatigue curves that are available. During the process, one issue regarding the effect of mean 
stresses on fatigue analysis, and how to consider the mean stress effect for elevated-temperature design, was brought up and discussed in the WG-CFNC.

High-temperate components under cyclic loading may experience mean stress effects. Mean stress can be categorized into either load-controlled or strain-controlled quantities. For load-controlled mean stress, such as that introduced by internal pressure, current $\mathrm{CF}$ design procedures (elastic or inelastic analysis route) account for creep damage introduced by sustained loading. Thus, the mean stress effect due to sustained primary loads shows up in the calculation of the life fraction used to enter the damage interaction diagram (Figure HBB-T-1420-2, "Creep-Fatigue Damage Envelope". On the other hand, the effect of mean stress under strain-controlled cycling is introduced by a non-zero mean strain. Mean stress under strain-controlled cyclic loading corresponds to cases such as welding residual stress or residual stress by thermal transients. Since the fatigue curves are based on fully reversed strain-controlled cycling, there is a negligible amount of mean stress during testing. To evaluate whether it is necessary to correct the design fatigue curves of Gr. 91 to account for the mean stress under strain-controlled cyclic loading, four critical tests were performed at ORNL. The evaluation compared the fatigue life of standard straincontrolled fatigue testing with zero initial mean stress, $N_{f}$, with that of fatigue testing with pre-straining introduced non-zero initial mean stress, $N_{f}^{\prime}$. Both tests should be cyclically loaded at the same strain range, strain rate, and temperature. These two types of tests are schematically illustrated in Fig. 2.

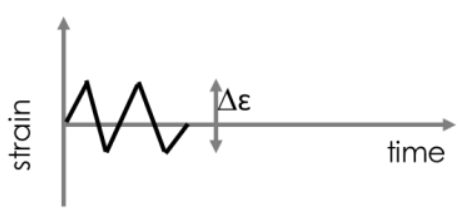

Strain controlled loading profile with zero initial mean stress (Fully reversed continuous fatigue, i.e., $R=-1$ on strain)

Cycle to failure, $\mathbf{N}_{\mathbf{f}}$

(a)

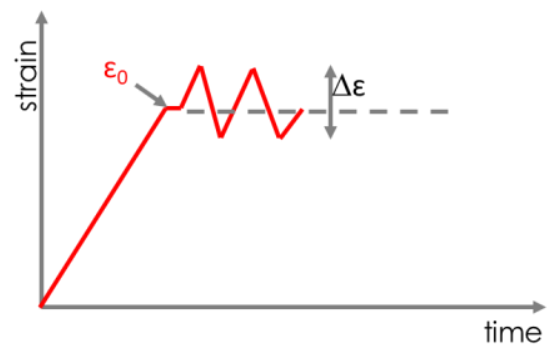

Strain controlled continuous, fully reversed cycling (with reference to $\varepsilon_{0}$ ), with non-zero initial stress, i.e., fatigue with mean stress

Cycle to failure, $\mathrm{N}_{\mathrm{f}}{ }^{\prime}$

(b)

Fig. 2. Schematics of strain-controlled fatigue testing with zero initial mean stress (a) and with non-zero initial mean stress.

\subsection{STRAIN-CONTROLLED MEAN STRESS TESTING PROCEDURE}

The tests were performed in accordance with the recommended test procedure by SWG Fatigue StrengthRecommended test procedure for fatigue testing of metallic materials below the creep range. Note that this recommended procedure was extended to high temperatures in this study. Tests with and without mean strain were performed under strain-controlled cyclic loading at temperatures of $540^{\circ} \mathrm{C}\left(1000^{\circ} \mathrm{F}\right)$ and $371^{\circ} \mathrm{C}\left(700^{\circ} \mathrm{F}\right)$. The details of the mean stress evaluation procedure are given below. 
1. Establish the $\Delta \varepsilon$ versus $N_{f}$, curve at $R=-1$, where $\Delta \varepsilon$ is the strain range, $N_{f}$ is the cycles to failure, $R$ is the strain loading ratio and equals (minimum strain amplitude)/(maximum strain amplitude) for one cycle.

2. Select a strain amplitude $(\Delta \varepsilon / 2)$ of interest in the long-life region and determine the stress range $(\Delta \sigma)$ at the start of the test at the selected $\Delta \varepsilon / 2$.

3. Determine the maximum mean stress to perform pre-strained fatigue testing.

Assume that the maximum possible tensile stress component is equal to the ultimate stress, $S_{u}$

$$
\sigma_{\max }=S_{u}
$$

since

$$
\sigma_{\min }=S_{u}-\Delta \sigma
$$

then the maximum possible mean stress is

$$
\left(\sigma_{\text {mean }}\right)_{\max }=\frac{\sigma_{\max }+\sigma_{\min }}{2}
$$

or

$$
\left(\sigma_{\text {mean }}\right)_{\max }=S_{u}-\frac{\Delta \sigma}{2}
$$

4. Perform a strain control test by first increasing the monotonic strain until the stress is equal to $\left(\sigma_{\text {mean }}\right)_{\text {max }}$ given by Eq. $(4)$.

5. Using the strain level identified in step 4, gradually increase the cyclic stress amplitude until it equals the value of $\Delta \varepsilon / 2$, selected in step 2 .

6. Continue the test to failure and determine the cycles to failure for mean stress testing, $N_{f}^{\prime}$.

In this study, the choice of the strain rate for cycling considered two factors: a higher strain rate should be used to minimize the duration of the testing time, and the choice of strain rate should not significantly affect the fatigue life cycles. In discussions in the WG-CFNC, the strain rate was initially determined to be $5 \mathrm{E}-3 / \mathrm{s}$ and was later increased to $1 \mathrm{E}-2 / \mathrm{s}$. Testing data for construction of the JSME fatigue curves suggest that the choice of strain rate between $1 \mathrm{E}-2 / \mathrm{s}$ and $1 \mathrm{E}-3 / \mathrm{s}$ does not significantly affect the fatigue life. In addition, the best fit JSME fatigue curves were used as the baseline reference for selection of the strain amplitude for this study. The selected strain range should result in a high-cycle-fatigue region. The corresponding strain range values for this study were $0.33 \%$ for testing at $540^{\circ} \mathrm{C}$ and $0.36 \%$ at $371{ }^{\circ} \mathrm{C}$, targeting cycles to failure larger than $1 \mathrm{E} 5$. The corresponding stress range, $\Delta \sigma$, of initial stabilized cycles was $526 \mathrm{MPa}$ at $540^{\circ} \mathrm{C}$ and $700 \mathrm{MPa}$ at $371^{\circ} \mathrm{C}$.

The ultimate tensile strength values are required to determine the applied mean stress according to the procedure. Tensile tests were performed on this heat of Gr. 91 at $540^{\circ} \mathrm{C}$ and $371^{\circ} \mathrm{C}$ and a strain rate of $5 \mathrm{E}-$ $3 / \mathrm{s}$. The tensile curves are plotted in Fig. 3. The tensile strength was $567.0 \mathrm{MPa}$ at $371^{\circ} \mathrm{C}$ and $467.6 \mathrm{MPa}$ at $540^{\circ} \mathrm{C}$. 
The maximum mean stress was calculated from Eq. (4). It was found to be $204.6 \mathrm{MPa}$ at $540^{\circ} \mathrm{C}$ and corresponded to the pre-straining level of $0.18 \%$. The maximum mean stress for $371^{\circ} \mathrm{C}$ was $217 \mathrm{MPa}$ at $0.15 \%$ pre-strain. Table 2 summarizes the testing parameters for both temperatures. Note that the initial non-zero mean stresses were below the yield strength for both test temperatures.

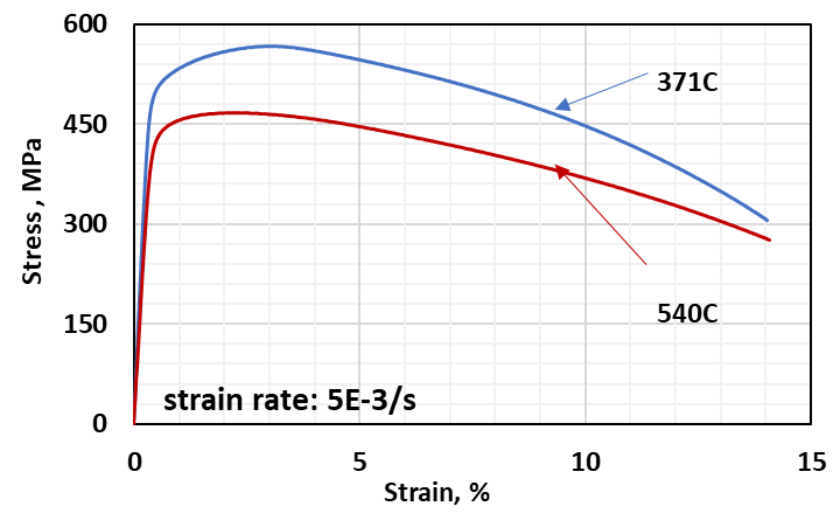

Fig. 3. Tensile stress-strain curves of Gr. 91 (heat 30176) at $540^{\circ} \mathrm{C}$ and $371^{\circ} \mathrm{C}$ and strain rate of $5 \mathrm{E}-3 / \mathrm{s}$.

Table 2. Testing parameters for strain-controlled mean stress evaluation on fatigue life of Gr. 91 (heat 30176) at $540^{\circ} \mathrm{C}$ and $371^{\circ} \mathrm{C}$.

\begin{tabular}{l|l|l|l|l|l}
\hline Test temperature & $\begin{array}{l}\text { Strain range, } \\
\boldsymbol{\Delta} \boldsymbol{\varepsilon}\end{array}$ & $\boldsymbol{\Delta} \boldsymbol{\sigma}$ & $\mathbf{R}$ ratio & $\begin{array}{l}\text { Initial mean } \\
\text { stress, }\end{array}$ & $\begin{array}{l}\text { Pre-straining } \\
\text { level, } \boldsymbol{\varepsilon}_{\mathbf{0}}\end{array}$ \\
\hline $371^{\circ} \mathrm{C}$ & $0.36 \%$ & $700 \mathrm{MPa}$ & -1 & $217 \mathrm{MPa}$ & $0.15 \%$ \\
\hline $540^{\circ} \mathrm{C}$ & $0.33 \%$ & $526 \mathrm{MPa}$ & -1 & $204.6 \mathrm{MPa}$ & $0.18 \%$ \\
\hline
\end{tabular}

\subsection{EVALUATION OF MEAN STRESS EFFECT ON THE FATIGUE DESIGN CURVES OF GR. 91}

The four tests were carried out until the failure criteria were met. Table 3 summarizes the failure criteria and the fatigue failure cycles of the four tests. The normalized stress ranges as a function of applied cycles for these four tests are compared in Fig. 4. The cycles to failure data points are plotted against the JSME best fit curve in Fig. 5. At both temperatures, this heat of Gr. 91 showed higher fatigue resistance than the average JSME best fit curves. At $540^{\circ} \mathrm{C}$, the test with pre-straining and non-zero initial mean stress lasted longer than the test with standard fatigue with zero initial mean stress, indicating mean stress correction is not needed at this temperature. At $371^{\circ} \mathrm{C}$, the non-zero mean stress fatigue showed slightly shorter life cycles than with standard fatigue, but the difference in fatigue was small and well within the data scatter for fatigue testing; therefore, it was concluded that the non-zero mean stress has a negligible effect on strain-controlled fatigue life at this temperature.

The representative hysteresis loops of the strain-controlled mean stress fatigue tests are compared with the standard fatigue tests in Fig. 6 and Fig. 7. For both temperatures, the first cycle of the non-zero mean stress fatigue test showed plastic deformation but decreased to near elastic from the second cycle. The 
initial non-zero mean stresses (shown as the ' + ' sign on the plots) decreased when the specimens were loaded with additional cycles.

Table 3. Summary of the test results of strain-controlled mean stress evaluation on Gr. 91 (heat 30176) at $540^{\circ} \mathrm{C}$ and $371^{\circ} \mathrm{C}$.

\begin{tabular}{c|c|c|c|c}
\hline \multirow{2}{*}{$\begin{array}{c}\text { Test } \\
\text { temperature }\end{array}$} & \multicolumn{2}{|c|}{ Fatigue with zero mean strain } & \multicolumn{2}{c}{ Fatigue with non- zero mean strain } \\
\cline { 2 - 5 } & $\begin{array}{c}\text { Cycles to } \\
\text { failure }\end{array}$ & Failure criteria & $\begin{array}{c}\text { Cycles to } \\
\text { failure }\end{array}$ & Failure criteria \\
\hline $371^{\circ} \mathrm{C}$ & $6.7 \mathrm{E} 6$ & $17 \%$ load drop runout & $5.07 \mathrm{E} 6$ & $\begin{array}{c}\text { Failure by fracture into two } \\
\text { parts with } 14 \% \text { load drop }\end{array}$ \\
\hline $540^{\circ} \mathrm{C}$ & $4.59 \mathrm{E} 5$ & $\begin{array}{c}\text { Failure by fracture into two } \\
\text { parts with } 17 \% \text { load drop }\end{array}$ & $1.3 \mathrm{E} 6$ & $17 \%$ load drop runout \\
\hline
\end{tabular}

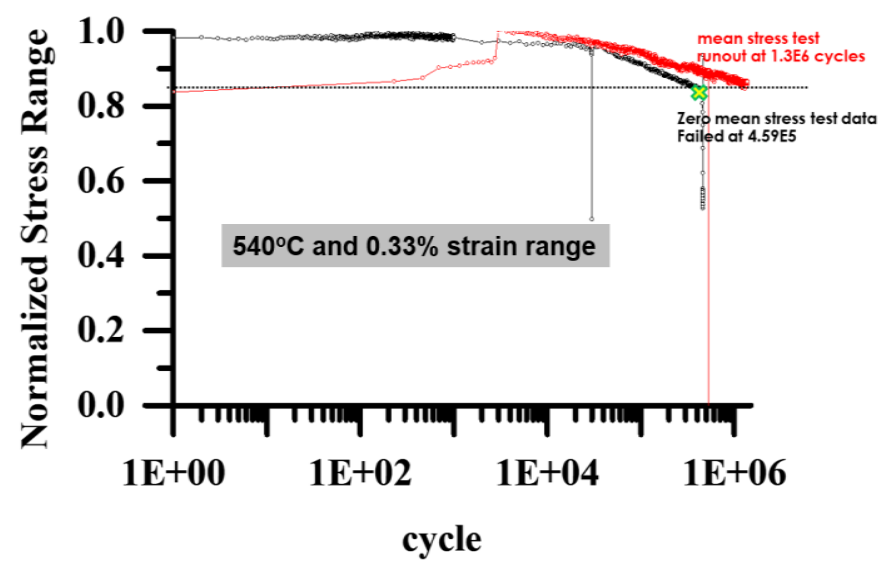

(a)

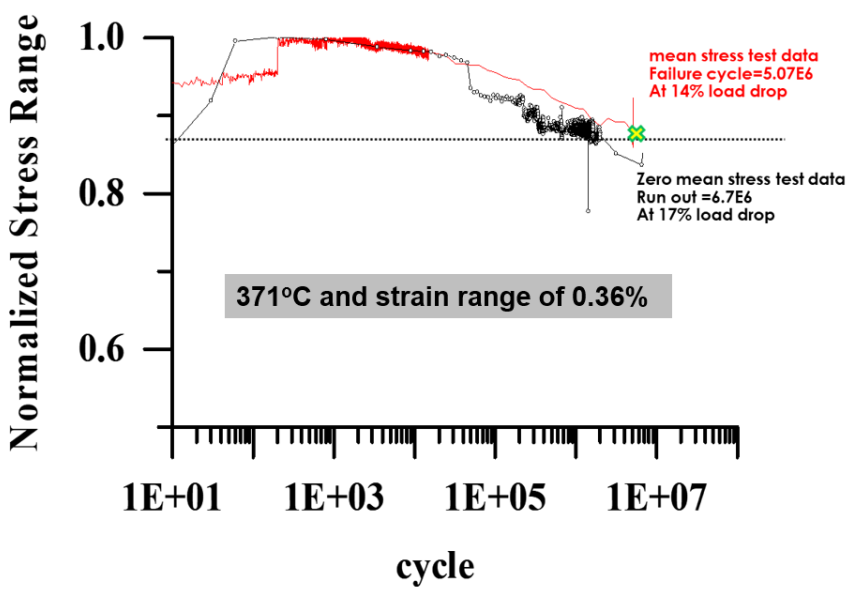

(b)

Fig. 4. Comparison of the stress ranges for strain-controlled fatigue tests with and without initial mean stress at $540^{\circ} \mathrm{C}$ (a) and $371^{\circ} \mathrm{C}$. 


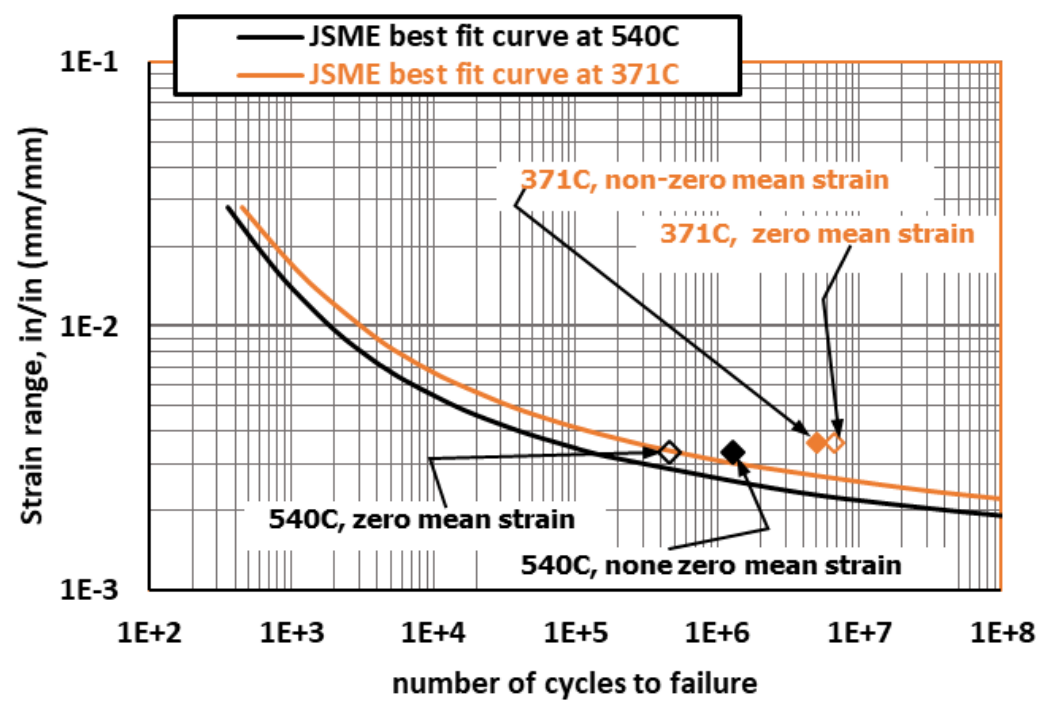

Fig. 5. Comparison of the strain-controlled mean strain fatigue test results with the JSME best fit curves for Gr. 91 at $540^{\circ} \mathrm{C}$ and $371^{\circ} \mathrm{C}$.

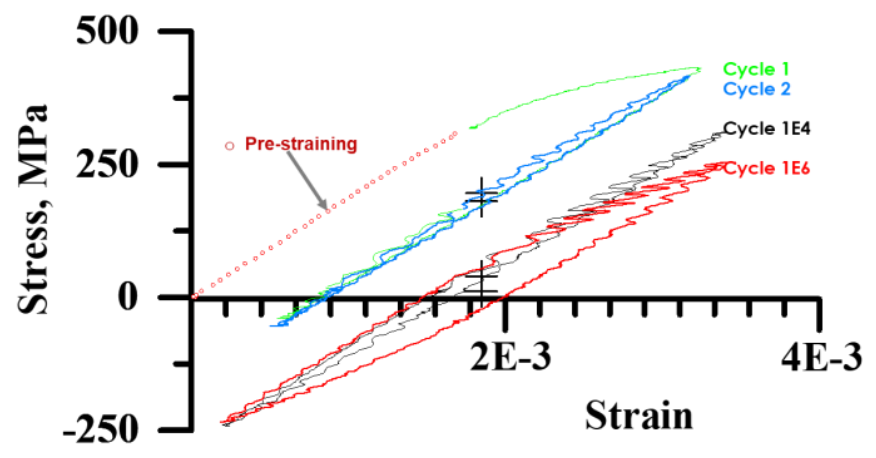

(a)

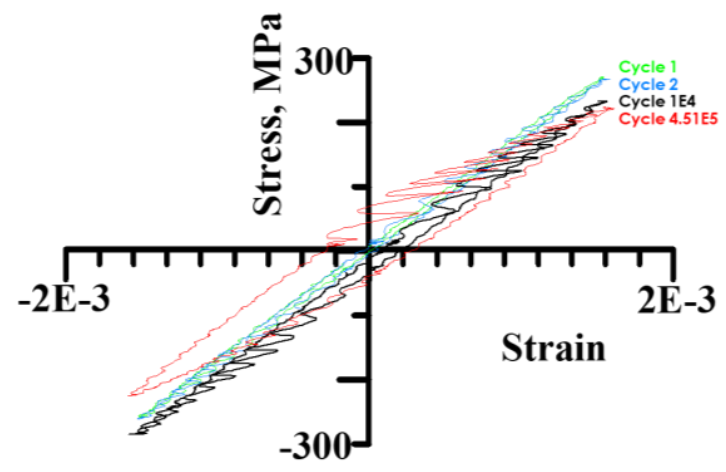

(b)

Fig. 6. Representative hysteresis loops of strain-controlled fatigue tests at $540^{\circ} \mathrm{C}$ for $\mathrm{Gr} .91$ (heat 30176 ). (a) with non-zero initial mean stress and (b) with zero initial mean stress. 


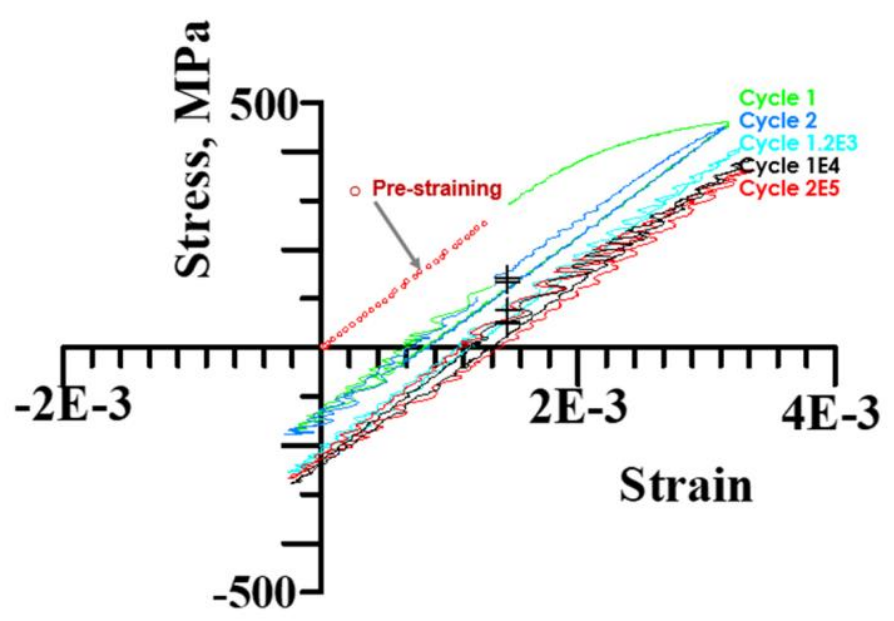

(a)

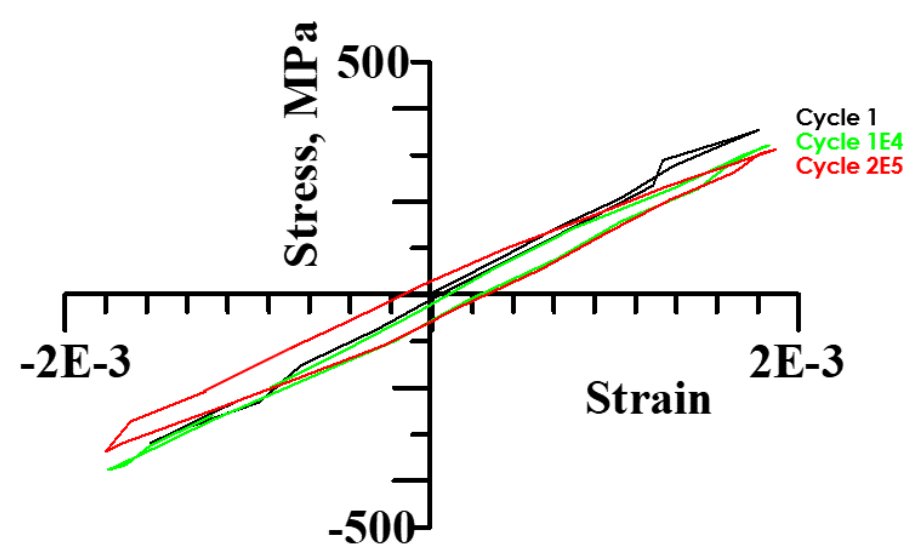

(b)

Fig. 7. Representative hysteresis loops of strain-controlled fatigue tests at $371^{\circ} \mathrm{C}$ for $\mathrm{Gr} .91$ (heat 30176 ). (a) with non-zero initial mean stress and (b) with zero initial mean stress.

The measured mean stresses as a function of loading cycles are compared for the four tests performed in this study in Fig. 8 and Fig. 9. At both test temperatures, the initial non-zero mean stress introduced by pre-straining quickly decreased as more strain-controlled cycles were applied. The initially applied maximum mean stress could not be sustained under stain-controlled cyclic loading. The decrease in the mean stresses as a function of applied cycles is more evidently shown in the linear plot scale. More than 99\% of the applied cycles had mean stress levels of $50 \mathrm{MPa}$ or less for the two strain-controlled fatigue tests with non-zero initial mean stress. Note also that the mean stresses for the standard strain-controlled fatigue tests with $\mathrm{R}=-1$ may deviate from zero for most of the cycles, but the mean stress level remained small for the duration of the tests.

It is interesting to note that despite the lower testing temperature of $371^{\circ} \mathrm{C}$ with negligible creep deformation, the decaying trend of the initial mean stress as a function of applied cycles had a remarkable resemblance to that at $540^{\circ} \mathrm{C}$. It is known that Gr. 91 is a cyclic softening material, and this cyclic softening effect may have played a rule in relaxing the mean stresses under the strain-controlled condition. 


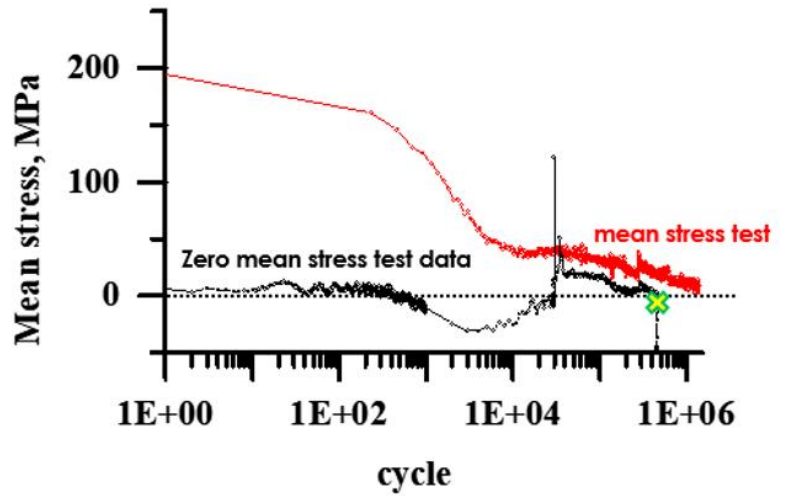

(a)

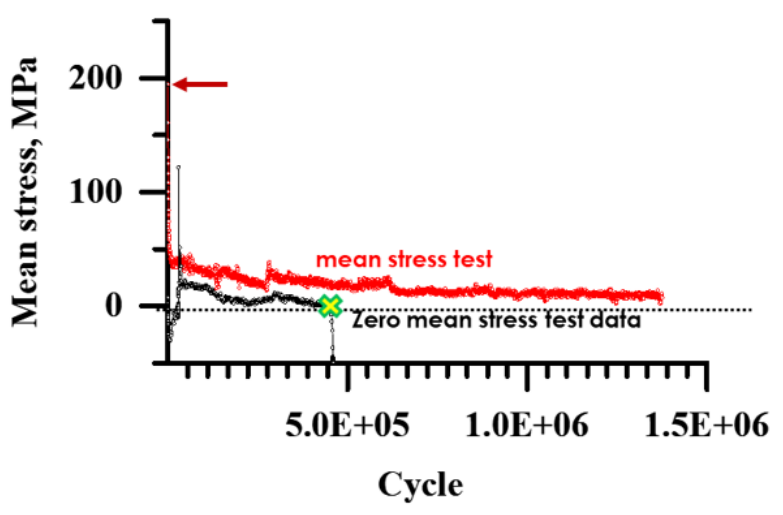

(b)

Fig. 8. Measured mean stresses as a function of loading cycles for mean strain effect testing at $540^{\circ} \mathrm{C}$ with applied cycles in logarithmic scale (a) and linear scale (b).

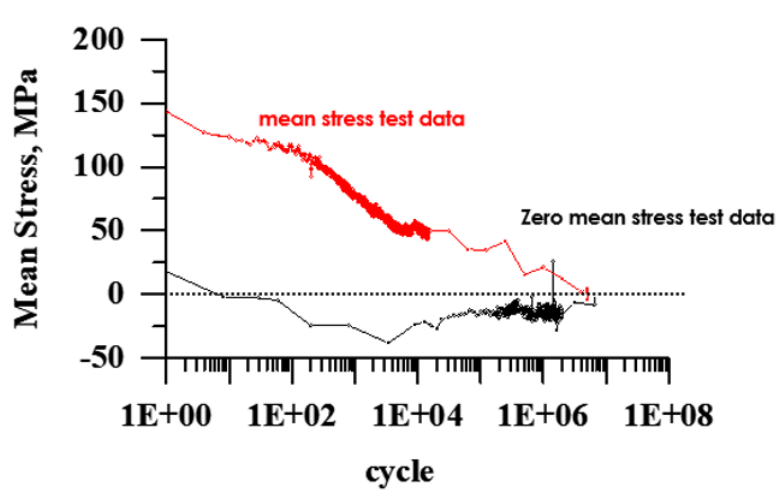

(a)

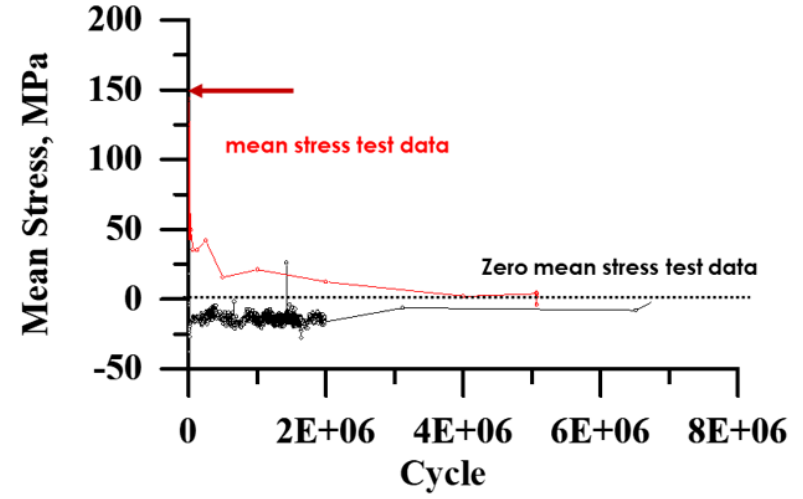

(b)

Fig. 9. Measured mean stresses as a function of loading cycles for mean strain effect testing at $371^{\circ} \mathrm{C}$ with the applied cycles in logarithmic scale (a) and linear scale (b).

In summary, current test data demonstrate a negligible effect of applied mean strain on strain-controlled fatigue life; i.e., strain-controlled cycling with non-zero mean strain does not reduce the cycle life compared with cycling with zero mean strain. Based on the above discussion, mean stress correction is not recommended for the fatigue design curves in Division 5 for Gr. 91.

\section{TESTING IN SUPPORT OF EXTENSION OF THE EPP STRAIN LIMITS CODE CASE TO GR. 91}

Code Case N-861 for strain limits evaluation and Code Case N-862 for CF evaluation using EPP methods have been approved for SS 304H and SS 316H in Section III, Division 5. Unlike SS 304H and SS 316H, 
Gr. 91 is a strong cyclic softening material. EPP analysis based on unsoftened material properties can potentially result in a lack of conservatism (Messner and Sham 2017, 2018). Experimental and modeling research is needed for extending the code cases to Gr. 91 for EPP analysis. Methods for modifying the EPP code cases to incorporate Gr. 91 have been established and explained in detail in reports by Messner and Sham 2017, 2018, 2019. A specially designed experiment was performed at ORNL to verify the method of modification of the EPP strain limits code case in support of the extension of the EPP methodology to Gr. 91. This section describes the experimental method and the results.

The effect of cyclic softening on the creep resistance of Gr. 91 was evaluated by introducing straincontrolled cyclic fatigue segments into the uniaxial creep test. The test method was the same as that explained in a previous report by Wang et al. 2017; it is schematically illustrated in Fig. 10. The red lines in Fig. 10 represent the creep segment and the blue lines are the strain-controlled fatigue segments.

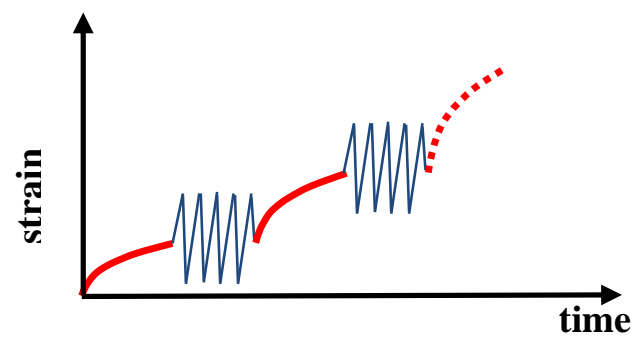

Fig. 10. Schematics of the experiment to evaluate the cyclic softening effect for Gr. 91 .

The effect of cyclic softening on creep rate was evaluated previously at $600^{\circ} \mathrm{C}$ and was reported in Wang et al. 2017. In that case, the specimen was first crept at $150 \mathrm{MPa}$ for $24 \mathrm{~h}$ and entered a steady state creep region; a strain-controlled cyclic fatigue segment of 100 cycles at a $1 \%$ strain range was then introduced. This process was repeated until the specimen failed. A stress level of $150 \mathrm{MPa}$ is estimated to result in a creep rupture life of more than $800 \mathrm{~h}$. The softening factor for modification of the isochronous stressstrain curves (ISSCs) determined from this test at $600^{\circ} \mathrm{C}$ was verified to agree with the modeling results (Messner and Sham 2017). The evaluation therefore concluded that at temperatures of $600^{\circ} \mathrm{C}$ and below, the softening factor calculated from the model was reasonable, since the model is based on the same softening mechanism.

However, the model initially predicted a very small softening factor for temperatures above $600^{\circ} \mathrm{C}$. To avoid excessive conservativeness after modifying for the softening effect, tests were performed to provide information on the softening effect on Gr. 91 (heat 30176) at $625^{\circ} \mathrm{C}$ and $650^{\circ} \mathrm{C}$ in this reporting period. The testing parameters are listed in Table 4 along with those for the previous test at $600^{\circ} \mathrm{C}$. For both temperatures, the stress levels selected for the creep segments are estimated to have rupture lives of more than $500 \mathrm{~h}$. The strain-controlled fatigue testing was performed with a $1 \%$ strain range and a $1 \mathrm{E}-3 / \mathrm{s}$ strain rate. The fatigue life cycles at the $1 \%$ strain range were estimated from the average fatigue curves of $\mathrm{Gr}$. 91, and they are 1300 and 1160 cycles.

Since the specimen was first loaded under constant load and crept to reach the steady state, the minimum creep rate of a non-softened Gr. 91 could be calculated. The creep rates with additionally introduced fatigue cycles were normalized with the unsoftened creep rate and are plotted in Fig. 11 for the three test temperatures. For all three testing cases, the creep rate was found to increase in the subsequent creep segment after additional fatigue cycles were introduced. 
Table 4. Summary of the test parameters of the cyclic softening effect on the creep rate of Gr. 91 (heat 30176 ).

\begin{tabular}{c|c|c|c|c|c|c}
\hline $\begin{array}{c}\text { Test } \\
\text { temperature }\end{array}$ & $\begin{array}{c}\text { Applied stress } \\
\text { for the creep } \\
\text { segment, MPa }\end{array}$ & $\begin{array}{c}\text { Minimum creep } \\
\text { rate of the non- } \\
\text { softened Gr. 91, } \\
\text { mm/mm/h }\end{array}$ & $\begin{array}{c}\text { Cyclic } \\
\text { loading } \\
\text { strain } \\
\text { range }\end{array}$ & $\begin{array}{c}\text { Estimated } \\
\text { fatigue life } \\
\text { at 1\% } \\
\text { strain range }\end{array}$ & $\begin{array}{c}\text { Total applied } \\
\text { number of } \\
\text { cycles before } \\
\text { creep failure }\end{array}$ & $\begin{array}{c}\text { Total } \\
\text { duration } \\
\text { of the test, } \\
\text { h }\end{array}$ \\
\hline $600^{\circ} \mathrm{C}$ & 150 & $2.5 \mathrm{E}-5$ & $1 \%$ & 1450 & 1100 & 294.1 \\
\hline $625^{\circ} \mathrm{C}$ & 130.6 & $5.4 \mathrm{E}-5$ & $1 \%$ & 1300 & 693 & 173 \\
\hline $650^{\circ} \mathrm{C}$ & 99.7 & $3.98 \mathrm{E}-5^{*}$ & $1 \%$ & 1160 & 743 & 90.4 \\
\hline
\end{tabular}

*Note: this value was from the stead state creep rate after 98 pre-cycles. The initial creep segment did not reach steady state.

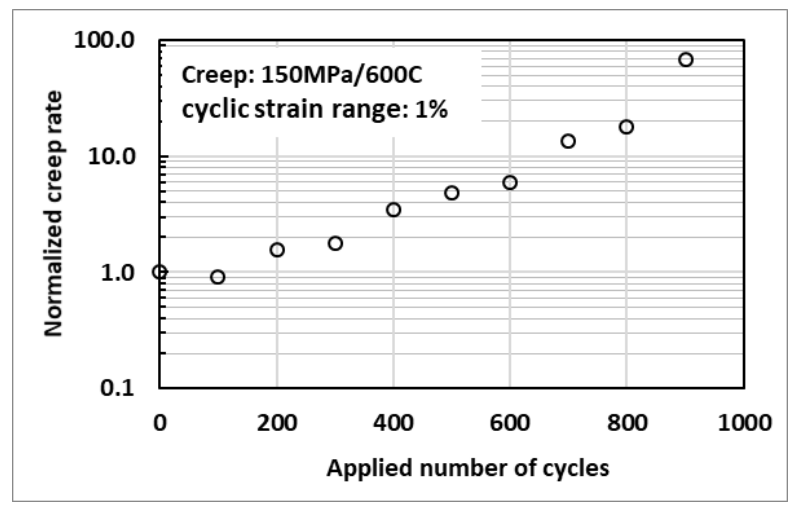

(a)

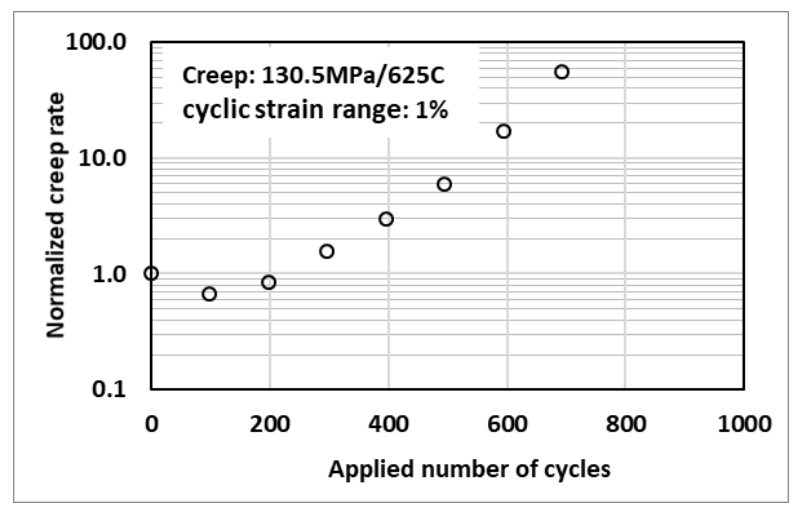

(b)

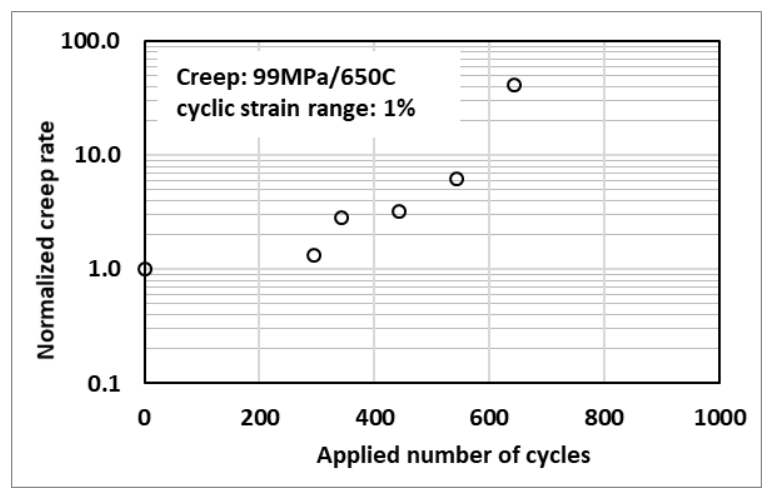

(c)

Fig. 11. Effect of cyclic softening on creep rate of $\mathrm{Gr} .91$ (heat 30176$)$ at $600^{\circ} \mathrm{C} \mathrm{(a),} 625^{\circ} \mathrm{C}(\mathrm{b})$, and $650^{\circ} \mathrm{C}(\mathrm{c})$.

The test results from tests of the softening effect on creep rates are plotted against the fatigue life fraction in Fig. 12. The fatigue life fraction is simply defined as the ratio of the applied number of fatigue cycles over the estimated fatigue life. When the Gr. 91 was pre-softened for half of the fatigue life fraction, the creep rate increased by $10 \times$ for all three temperatures. The overall tends of the cyclic softening effects on 
the creep rates were consistent for the three test temperatures, indicating a similar controlling mechanism for the softening effect at these temperatures.

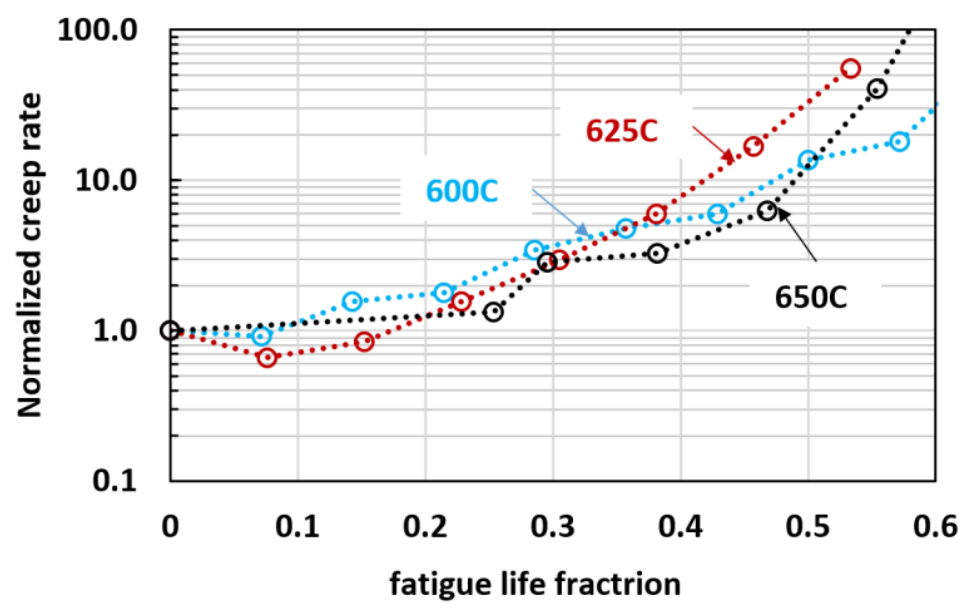

Fig. 12. Effect of cyclic softening on creep behavior of Gr. 91 (heat 30176).

\section{PROGRESS IN DEVELOPMENT OF ALTERNATIVE CREEP-FATIGUE EVALUATION METHOD FOR GR. 91}

\subsection{DEVELOPMENT OF INTEGRATED EPP-SMT CF EVALUATION METHODOLOGY}

The current ASME code rules for evaluation of CF evaluation based on the damage diagram require the separate evaluation of creep damage and fatigue damage by placing a limit on the allowable combined damage, the D diagram, based on the calculated individual damages. The uncertainties in the separate evaluation of the creep damage and fatigue damage from the test data lead to the use of overly conservative design factors in the current CF procedure. The difficulties and the excessive conservatism in the $\mathrm{D}$ diagram approach for creep fatigue evaluation are what led to the development of this alternative CF evaluation methodology, i.e., the integrated EPP analysis and SMT design methodology. The goal of this integrated EPP-SMT methodology is to maximize the advantages of both EPP methods and the SMT $\mathrm{CF}$ evaluation approach, which avoids separate evaluation of creep and fatigue damage, eliminates the requirement for stress classification in current methods, and greatly simplifies the evaluation of elevatedtemperature cyclic service.

The development of an SMT-based design curve requires a significant amount of SMT test data. Experimentally, SMT key feature CF testing has been fully developed and successfully tested for Alloy 617, SS 316H, SS 304H, and Gr. 91 (Wang et al. 2013a, 2014, 2015, 2016a, 2017b, 2017c). The testing of the SMT key feature CF test articles was designed to evaluate the effects of elastic follow-up, stress concentration factor, primary load, strain range, loading rate, test temperature, and hold time. However, testing with the key feature SMT specimens requires specialized and costly instrumentation. Even more critical, the stress and strain redistribution for the SMT key feature test articles is complex; and it is difficult to extract information to support the modeling analysis. To advance the design method, major effort was invested in FY 2018 in developing improved testing techniques to facilitate SMT-based CF testing. The new techniques, TBSMT and SBSMT, both enable the use of standard CF specimens. The testing concept is explained in Wang et al. 2018a and 2019a, and the techniques are successfully verified for Alloy 617 and SS 316H in Wang et al. 2019a, 2019b. The following sections describe experiments 
designed and performed on Gr. 91 (heat 30176) using TBSMT and SBSMT to support the extension of the integrated EPP-SMT design method to Gr. 91.

\subsection{SMT CREEP-FATIGUE TESTING ON GR. 91}

The Gr. 91 specimen for SMT CF experiments used the standard CF geometry shown in Fig. 1. The enddisplacement loading profile for one cycle is schematically shown in Fig. 13. The loading started either with the compression holding segment or the tensile loading segment; but the two loading profiles were essentially the same because repeating cycles were applied for the CF testing. The specimen was loaded at a nominal strain rate of $1 \mathrm{E}-3 / \mathrm{s}$ with a compression hold time of $600 \mathrm{~s}$. The test was fully reversed with a strain ratio $\mathrm{R}$ of -1 . The tests were automated through a LabView program. The testing temperature was $650^{\circ} \mathrm{C}$ for all the tests performed in this report.

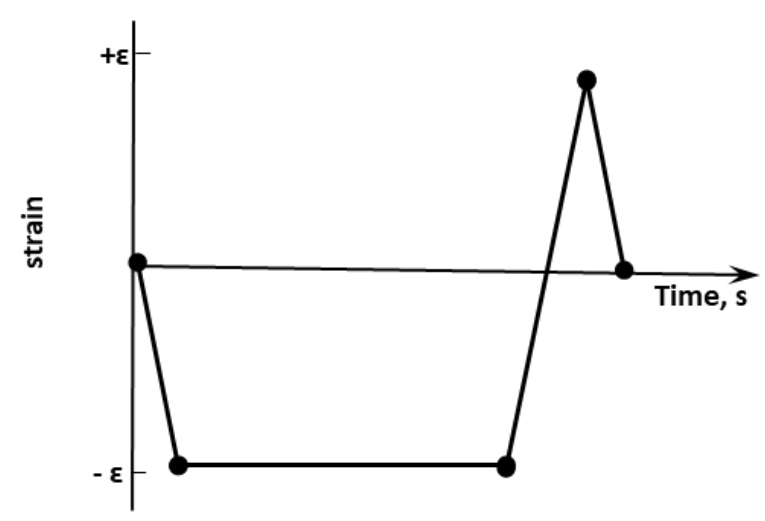

(a)

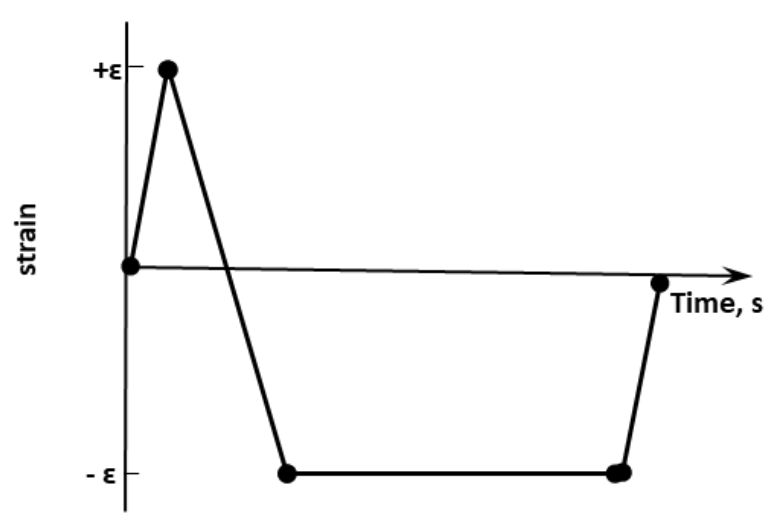

(b)

Fig. 13. Applied CF loading profiles for one cycle with compression hold. Starting with compression holding segment (a) or the tension loading segment (b)

\subsection{TBSMT CREEP-FATIGUE ON GR. 91 WITH A ROOM-TEMPERATURE DRIVER BAR}

The TBSMT technique can be designed to use a driver bar at room temperature (i.e., fully elastic) or at high temperature (i.e., a creeping driver bar) to represent the desired elastic follow-up effect. The results are discussed in this section.

Test no. TB03 used a room-temperature driver bar and test specimens at $650^{\circ} \mathrm{C}$. The test was performed to failure. The stress-strain relationship of the room-temperature driver bar is shown in Fig. 14. The slope of $206 \mathrm{GPa}$ is the same value as the elastic module of the material at room temperature. This information was used confirm the TBSMT configuration and test design to be correct.

The elastic follow-up factor, Q, for test TB03 was calculated from the compression hold stress-strain curves, and the value was 3.5. Plots of the strain range and maximum/minimum stresses as a function of applied cycles are shown in Fig. 15. The results show that the strain ranges measured at the test section will increase as a function of the applied cycle. The increase in the strain ranges and decrease in the maximum and minimum stresses became rapid at 2050 cycles, where the specimen approached the last stage toward failure. The stress history of the first five cycles and the representative hysteresis loops are 
also presented in Fig. 15. For this test, the $600 \mathrm{~s}$ hold time did not reach saturation, as seen in Fig. 15c. Cycle number 1000 is the mid-life cycle for this test. The representative hysteresis loops in Fig. 15c show that the elastic follow-up factor, represented by the linear relaxation slope during the compression holding, was constant for this compression holding segment; and there were no significant changes in the elastic follow-up with more applied cycles.

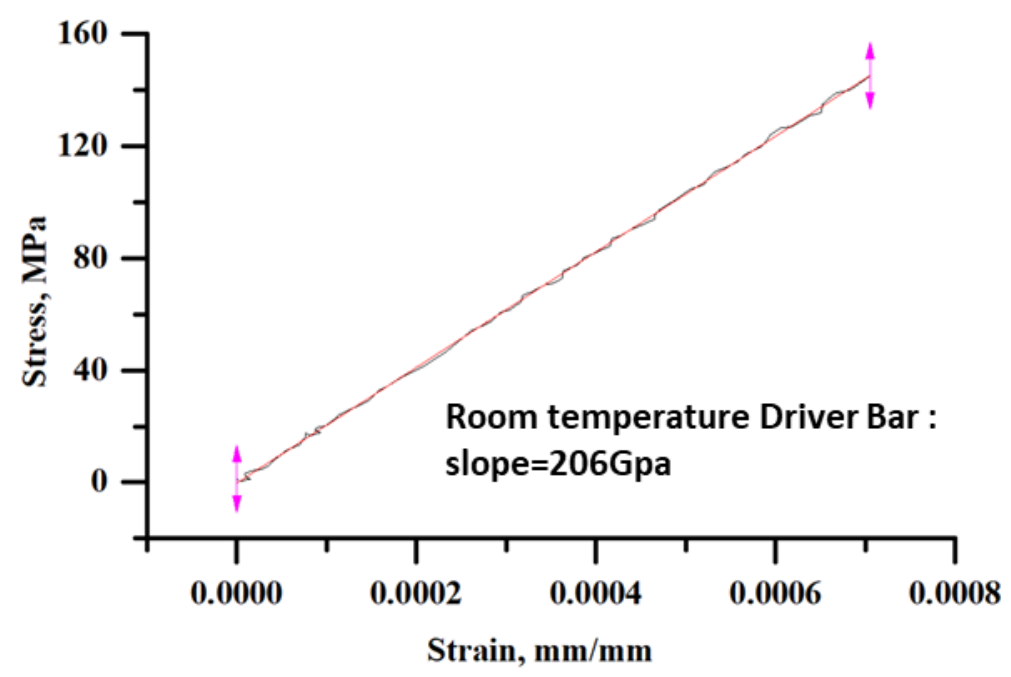

Fig. 14. Stress-strain curves of the room-temperature driver bar for TB03.

During the compression holding segment, the stress relaxed. If we define the stress relaxation ratio for the hold period as $\left(1-\sigma_{f} / \sigma_{o}\right)$, where $\sigma_{o}$ is the stress at beginning of the holding and $\sigma_{f}$ is the stress at the end of the holding, the stress relaxation behavior can be assessed. The stress relaxation ratios as a function of cycle number were calculated and are plotted in Fig. 16. The stress relaxation ratio was large for the initial cycles but reached a saturation or steady state after about five cycles. For the steady state, the stress relaxation ratio showed an insignificant increase as a function of the applied cycles; but it showed a sharp increase starting at about 2050 cycles. The measured strain ranges and stress ranges were normalized with the initial values and plotted in the same figure. The results show that the fast increase in strain ranges agrees well with the fast drop in the stress ranges. The sharp transition is where failure initiation is defined.

A picture of failed specimen TB03 is shown in Fig. 17. The failure was through necking at the center of the gage section. 


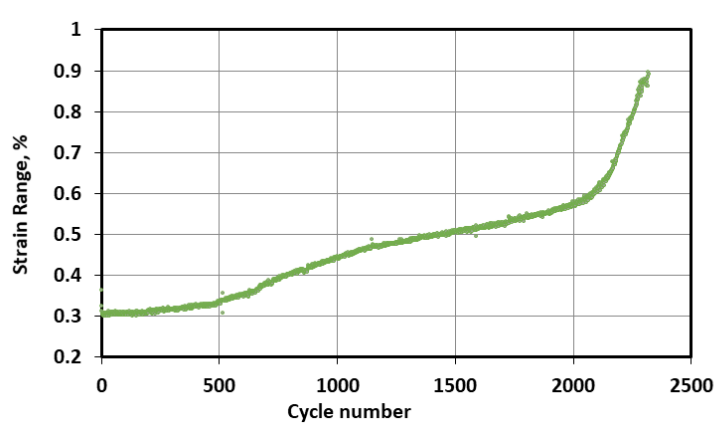

(a)

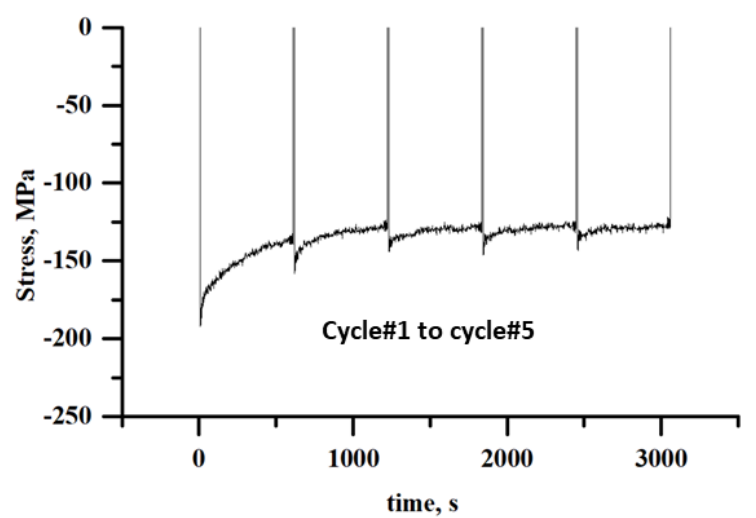

(c)

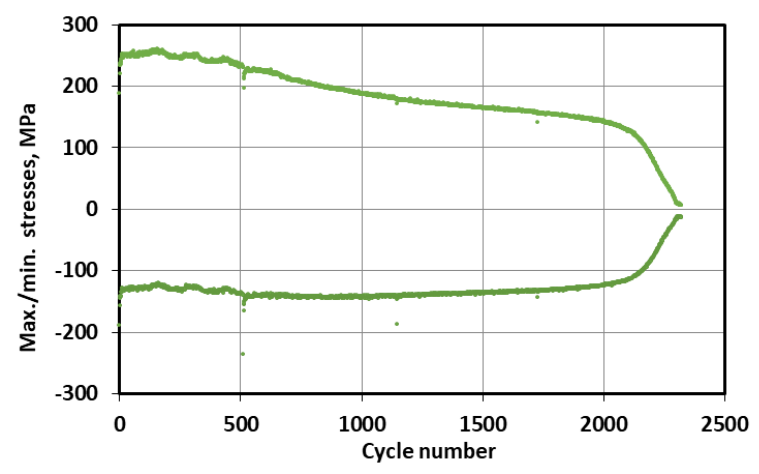

(b)

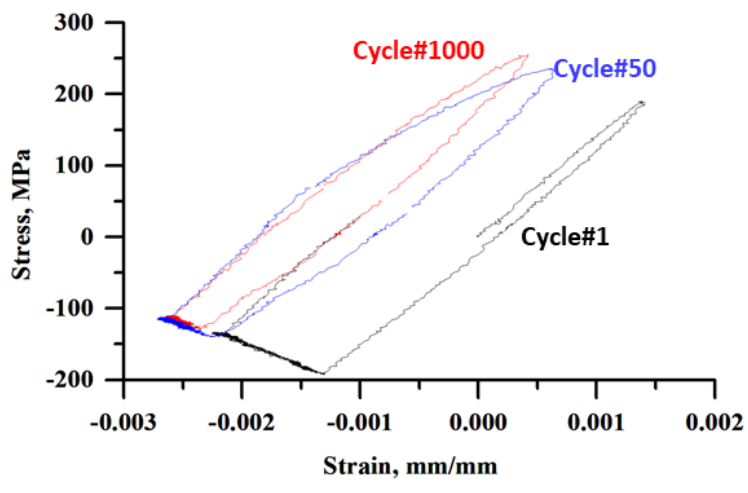

(d)

Fig. 15. Plots of the strain ranges (a), maximum/minimum stresses (b), and stress history of the first five cycles (c) and the representative hysteresis loops (d) for $\mathrm{TB} 03$ at $650^{\circ} \mathrm{C}$.

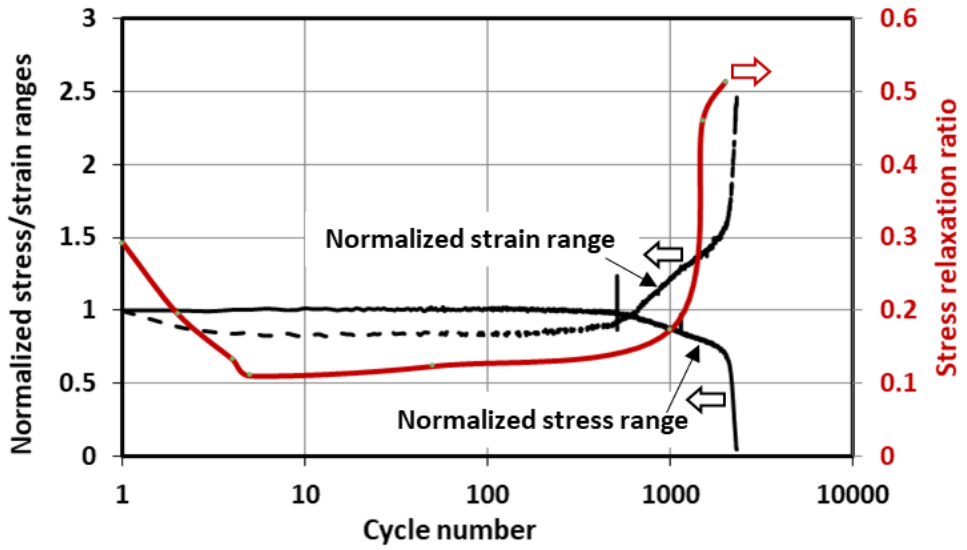

Fig. 16. Normalized strain range, stress range, and stress relaxation ratio for $\mathrm{TB} 03$. 


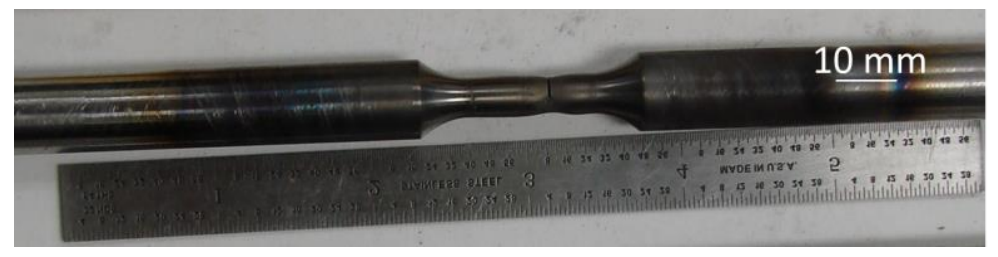

Fig. 17. Photograph of the failed TB03 specimen.

Tests TB07 and TB08 were also performed using a room-temperature driver bar. TB07 had an elastic follow-up of 4.1, slightly higher than that of TB08, which had the same elastic follow-up of 3.5 as TB03. The strain ranges, maximum and minimum stresses, and hysteresis loops of cycle \#400 are compared in Fig. 18.

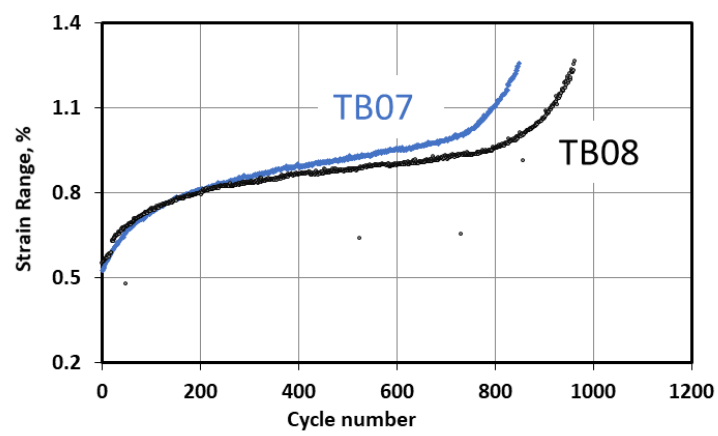

(a)

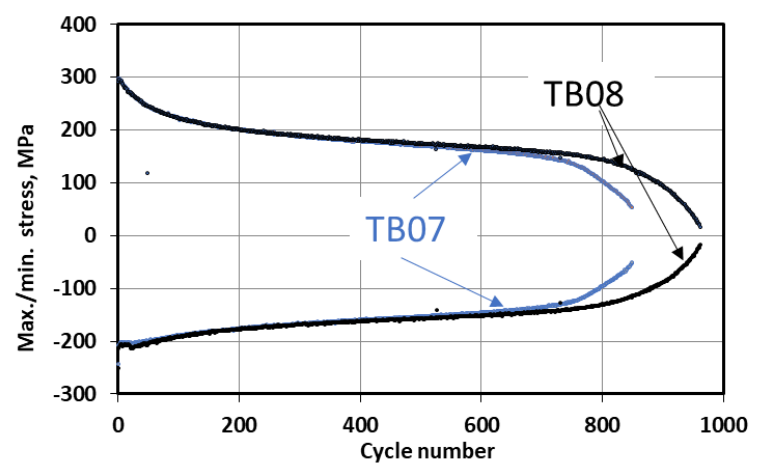

(b)

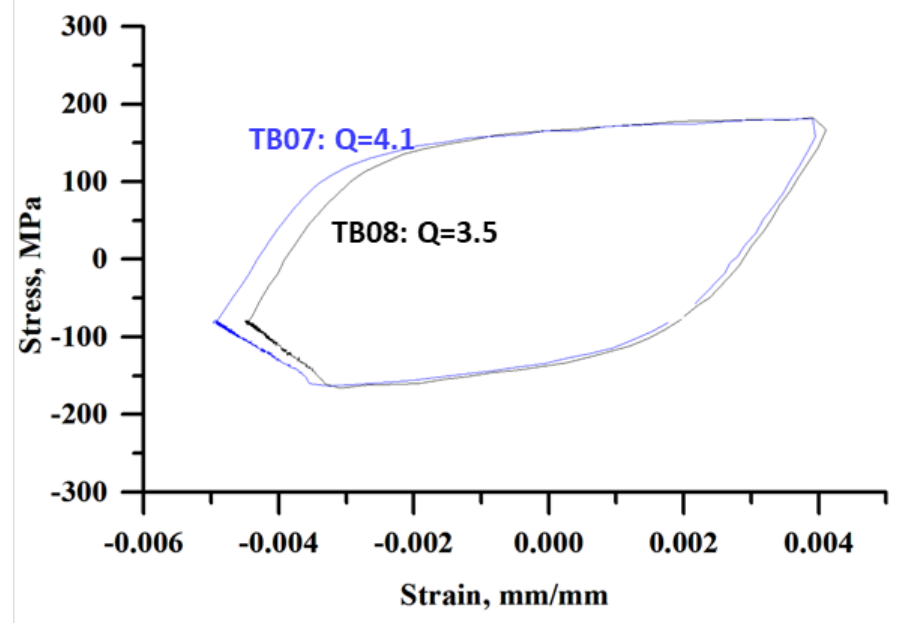

(c)

Fig. 18. Plots of the strain ranges (a), maximum/minimum stresses (b), and hysteresis loops of cycle \#400 (c) for $\mathrm{TB} 07$ and $\mathrm{TB} 08$ at $650^{\circ} \mathrm{C}$. 
The initial stable strain ranges were similar, with $0.53 \%$ for TB07 and $0.55 \%$ for TB08; and the numbers of cycles to failure were 750 for TB07 and 800 for TB08. The slight larger Q with a slight smaller initial strain range for TB07 did show a shorter SMT CF life, but the effect was not significant under the test conditions.

\subsection{TBSMT CREEP-FATIGUE ON GR. 91 WITH A CREEPING DRIVER BAR}

TBSMT with a high-temperature driver bar can simulate the scenario in which the entire component is at high temperature and the elastic follow-up effect is caused by parts at high temperature that may creep over time. TB10 was performed with both the driver bar and the test specimen at $650^{\circ} \mathrm{C}$. The strain ranges, maximum/minimum strains, maximum/minimum stresses, and representative hysteresis loops are plotted in Fig. 19. The initial stable strain rage was 0.55\%. However, comparing TB07 and TB08, TB10 showed much fewer cycles to failure - 480 cycles. The specimen showed tensile ratcheting strain as a function of applied fatigue cycles, with the fast ratcheting at the initial cycles. An increase in the strain ranges as a function applied cycles was observed.

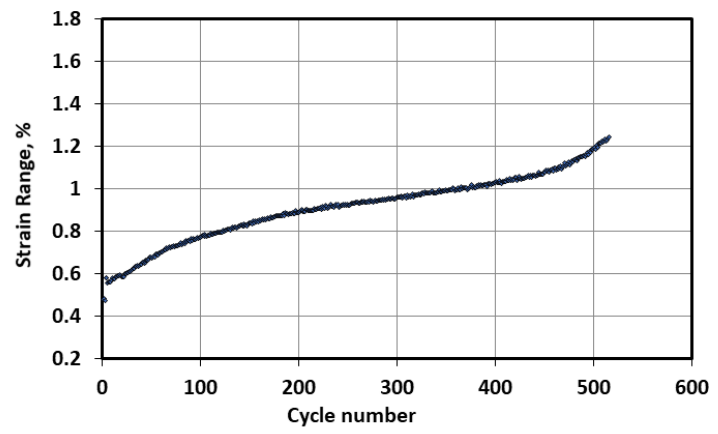

(a)

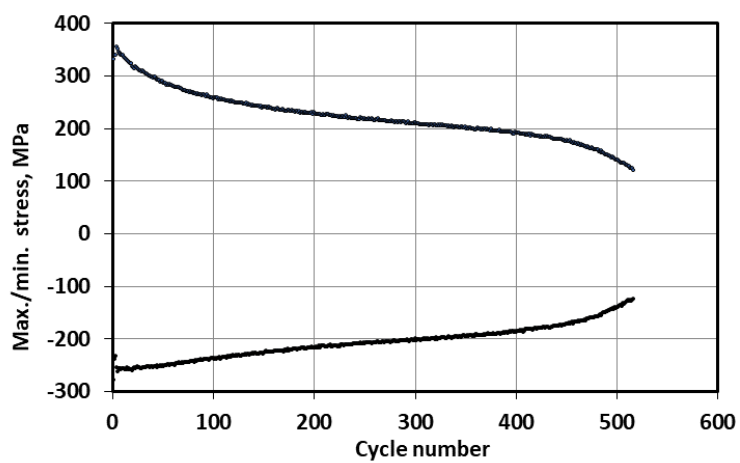

(c)

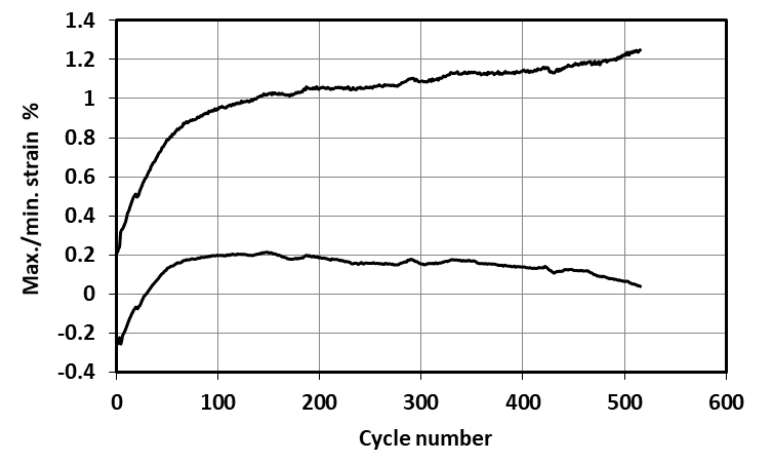

(b)

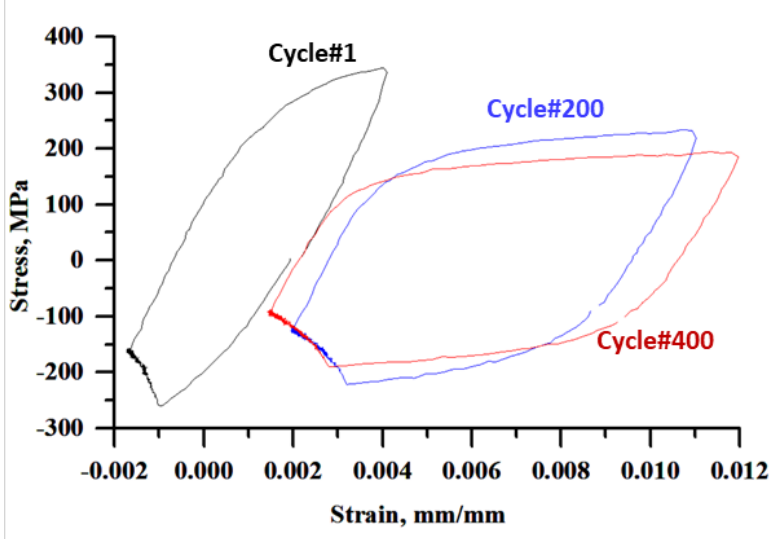

(d)

Fig. 19. Plots of the strain ranges (a), maximum/minimum strains (b), maximum/minimum stresses (c) and the representative hysteresis loops (d) for $\mathrm{TB} 10$ at $650^{\circ} \mathrm{C}$. 
A closer examination of the compression holding segment revealed additional differences between this test and those performed with a room-temperature driver. The hold segment of cycle \#200 is plotted in Fig. 20. The stress relaxation was found to be nonlinear. The elastic follow-up factor increased from the value of 2.1 at the beginning of holding to a value of 4.7 at the end of holding. If the secant slope between the start point and the end point of the holding is used as the basis for the elastic follow-up factor, it will result in an elastic follow-up factor of 3. Based on the limited test results and the comparison between this test and TB07 and TB08, the secant elastic follow-up factor of 3 would significantly underestimate the elastic follow-up effect. The reason is that the stress relaxation at the beginning of the holding segment is fast, and the specimen spends most part of the holding period at the larger Q region.

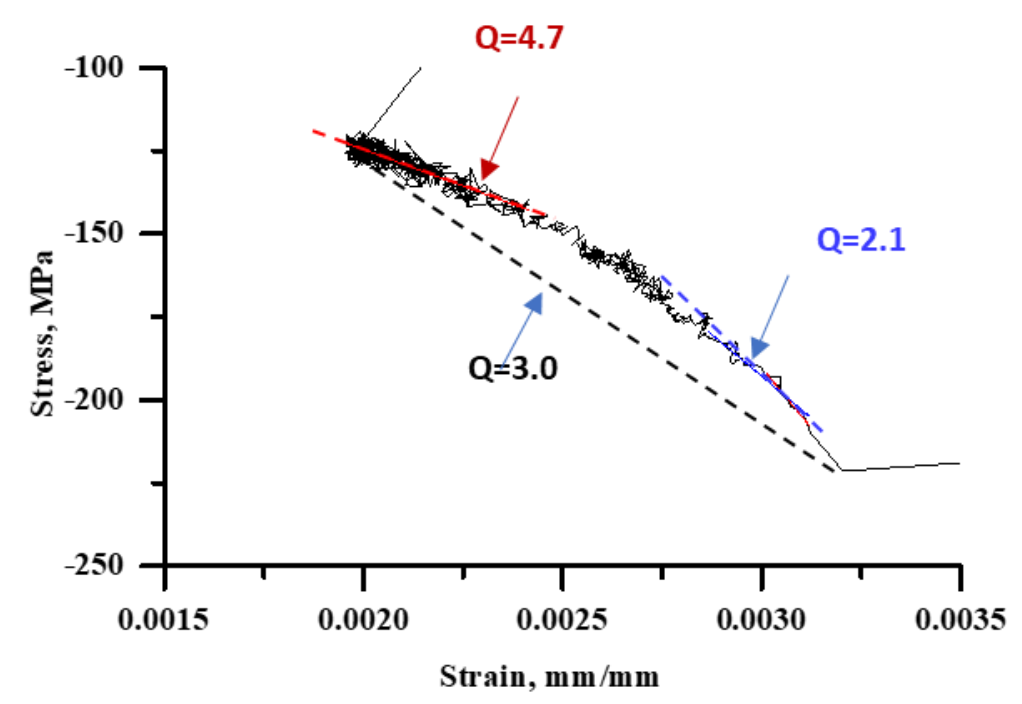

Fig. 20. Details of the stress relaxation during hold segment of cycle \#200 for TB10.

\subsection{SBSMT TEST RESULTS ON GR. 91}

In this reporting period, four SBSMT tests were performed to failure on Gr. 91 (heat 30176) at $650^{\circ} \mathrm{C}$. Test SB05 had an elastic follow-up of 3.8, and the other three tests had high elastic follow-up factors of 12. All the specimens were loading and had the profile shown in Fig. 13a. The holding time was $600 \mathrm{~s}$ and the nominal strain rate was $1 \mathrm{E}-3 / \mathrm{s}$.

Plots of the strain ranges, maximum/minimum stresses, and representative hysteresis loops for SB05 are shown in Fig. 21. The initial strain range was $0.54 \%$ and it gradually increased with more applied cycles. The specimen showed cycles to failure of 680, consistent with the results from TB07 and TB 08. As demonstrated by the hysteresis loops, the elastic follow-up was constant during the holding segment and remained at the same value till failure. The maximum and minimum stresses and the hysteresis loops of cycle \#200 for SB05 and TB07 are also compared in Fig. 22, showing similar characteristics in terms of the constant relaxation slope of the stress-strain curves and the trend of the maximum and minimum stresses. SB05 had slightly smaller strain range at cycle \#200 than TB07 which could be due to differences between the two specimens. From these results, it is concluded that the SBSMT testing technique is essentially the same as the TBSMT with cold driver bar. Since SBSMT uses one test 
machine and standard creep-fatigue specimen geometry, it is much simpler to be applied and therefor has more advantages in terms of being generalized as a SMT based technique.

Test results for SB09 and SB10 are compared in Fig. 23. These two tests had the same elastic follow-up factor of 12 . The initial strain range was $0.7 \%$ for SB09 and slightly lower for SB10 at $0.62 \%$. The purpose of testing the two specimens at close strain ranges was to evaluate the consistency of the testing procedure. The results were consistent in terms of evolution of the strains and stresses as a function of applied cycles and the similar characteristics of the hysteresis loops. The cycles to failure were 250 for SB09 and 330 for SB10.

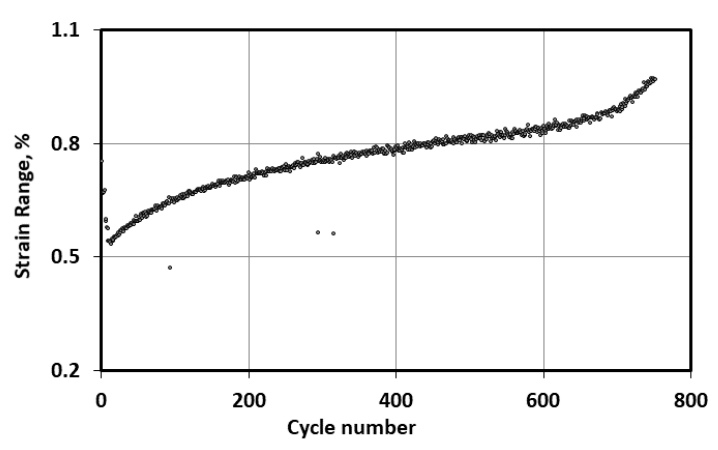

(a)

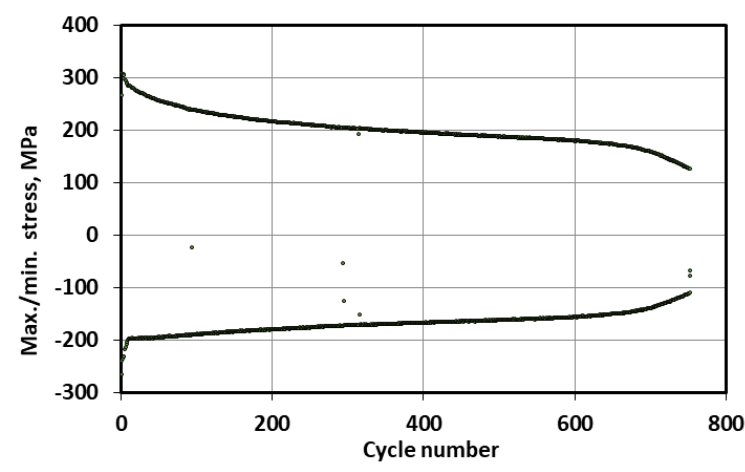

(b)

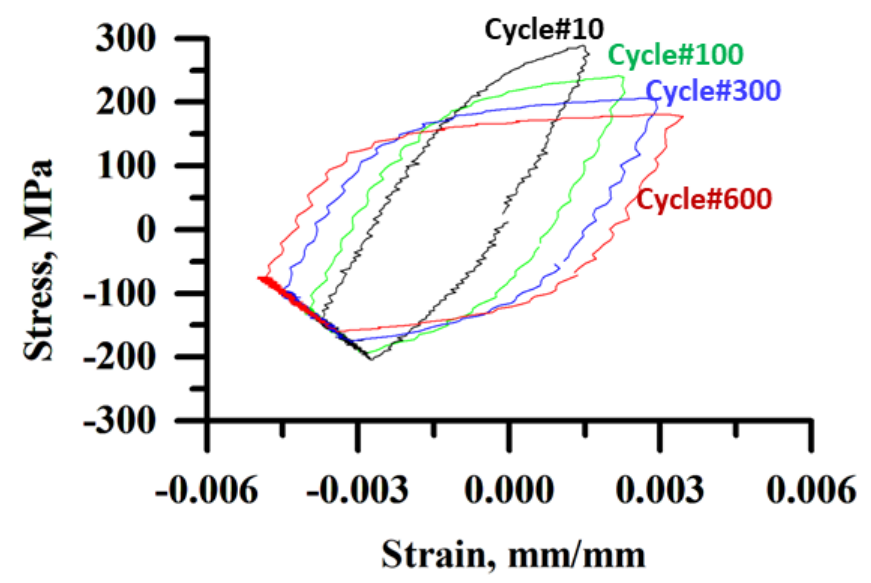

(c)

Fig. 21. Plots of the strain ranges (a), maximum/minimum stresses (b), and representative hysteresis loops (c) for $\mathrm{SB05}$ at $650^{\circ} \mathrm{C}$. 


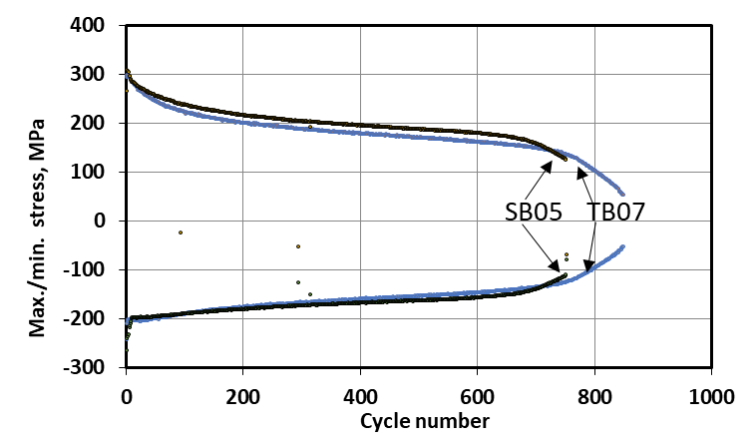

(a)

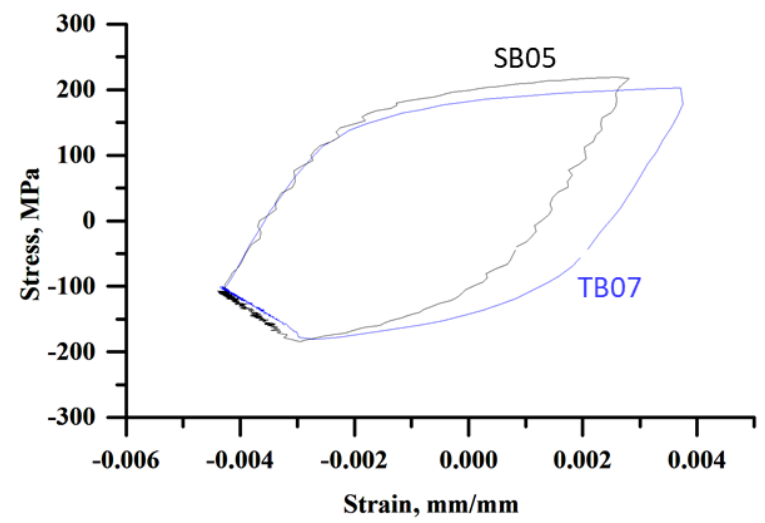

(b)

Fig. 22. Comparison of the maximum and minimum stresses (a) and hysteresis loops of cycle \# 200 (b) for SB05 and TB07.

Test SB11 with an elastic follow-up factor of 12 was performed to failure at $650^{\circ} \mathrm{C}$ with a small initial strain range of $0.25 \%$. Test SB11 lasted 45 days with cycles to failure of 6200 . The results are presented in Fig. 24. The elastic follow-up was maintained at the same value throughout the entire test, as demonstrated through the hysteresis loops in Fig. 23. This test demonstrated that the testing technique of SBSMT was stable and valid for intermediate to long-term CF evaluation. Unlike the test with a smaller elastic follow-up factor, the stress history shows that the stress relaxation was much slower, and a saturation state was not reached for the $600 \mathrm{~s}$ holding segment. The cyclic softening effect is evidently shown in the stress range plot. Interestingly, the specimen ratcheted initially to the compressive strain direction before mid-life cycles of about 3000 and then switched and ratcheted to the tensile direction, which is consistent with the evolution of the maximum/minimum stresses.

The cyclic softening effect was shown to be different at different strain range levels. The three tests with the same elastic follow-up factor of 12 are compared by plotting the normalized stress ranges as a function of fatigue life fraction in Fig. 25. The results show that the cyclic softening effect is larger at the large strain ranges. 


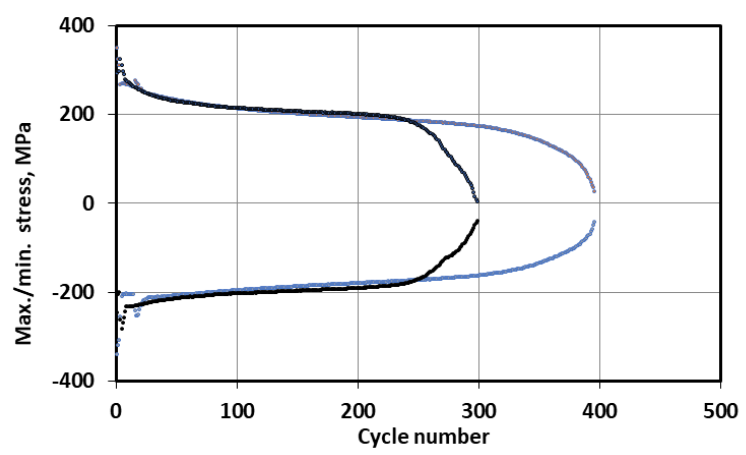

(a)

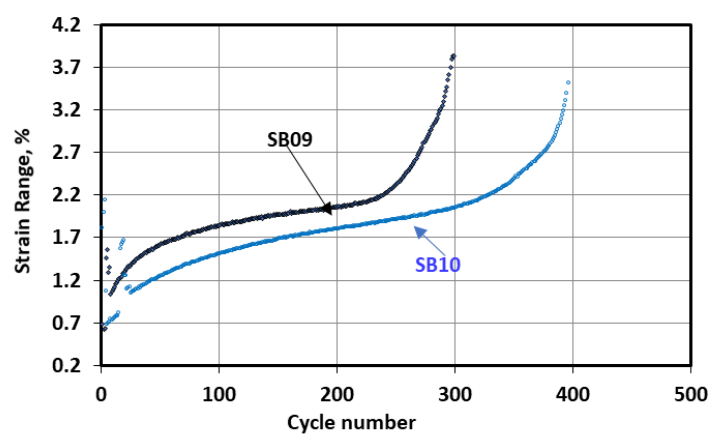

(c)

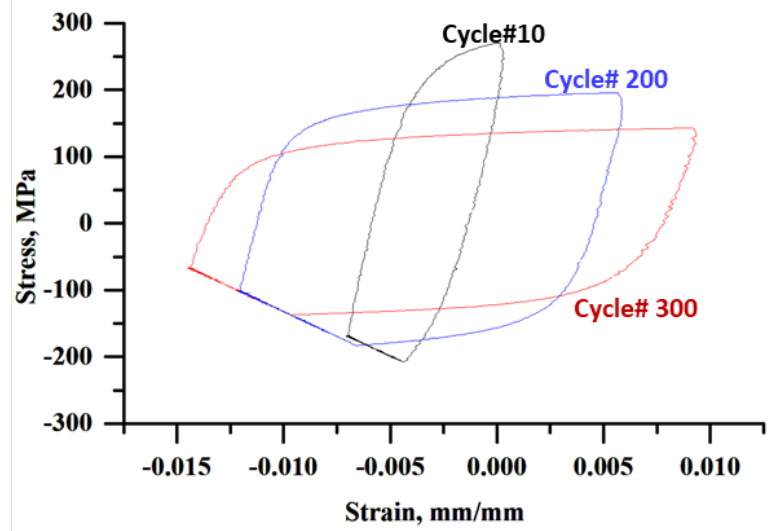

(e) SB09

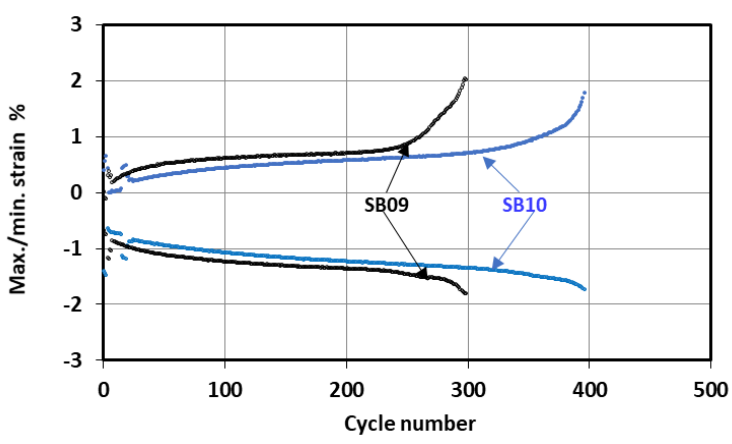

(b)

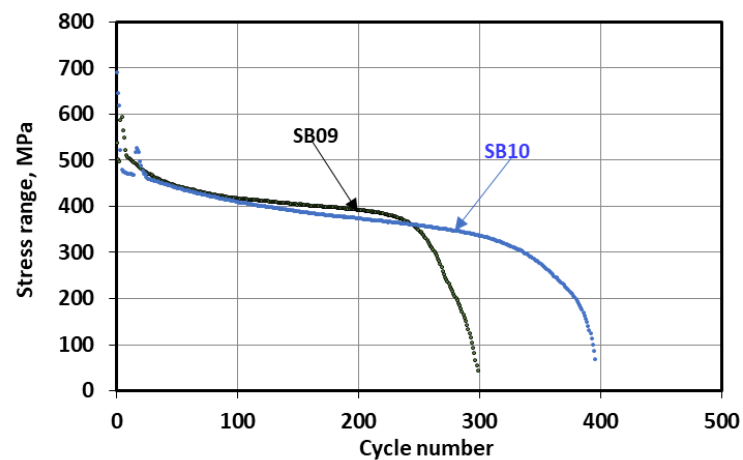

(d)

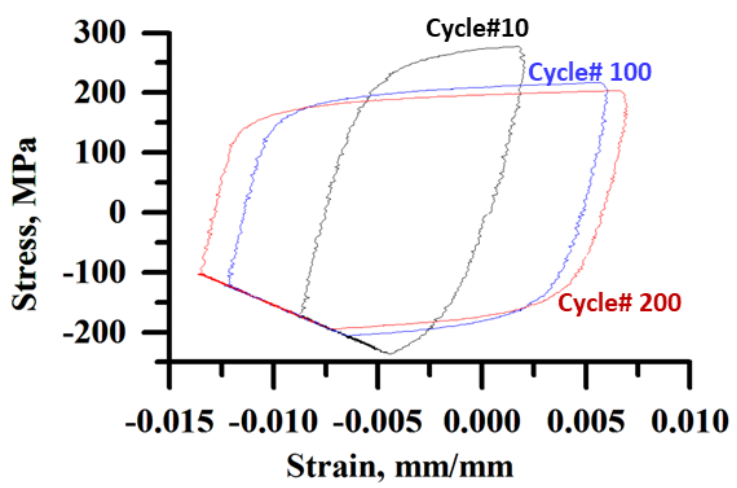

(f) $\mathrm{SB} 10$

Fig. 23. Plots of the maximum/minimum stresses (a), maximum/minimum strains (b), strain ranges (c), stress ranges (d) for $\mathrm{SB09}$ and $\mathrm{SB10}$, and representative hysteresis loops for SB09 (e) and SB10 (f). 


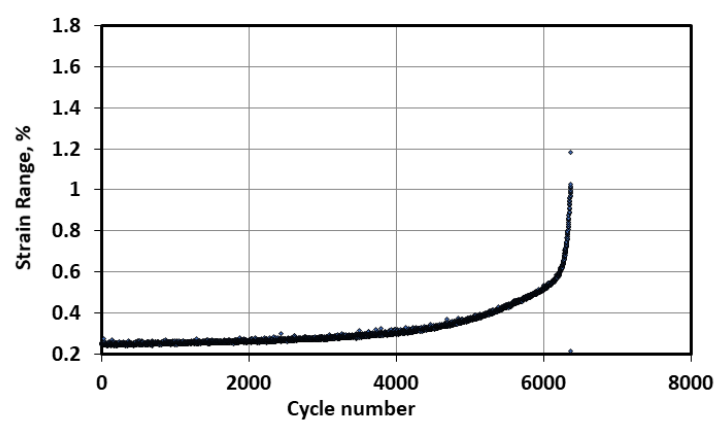

(a)

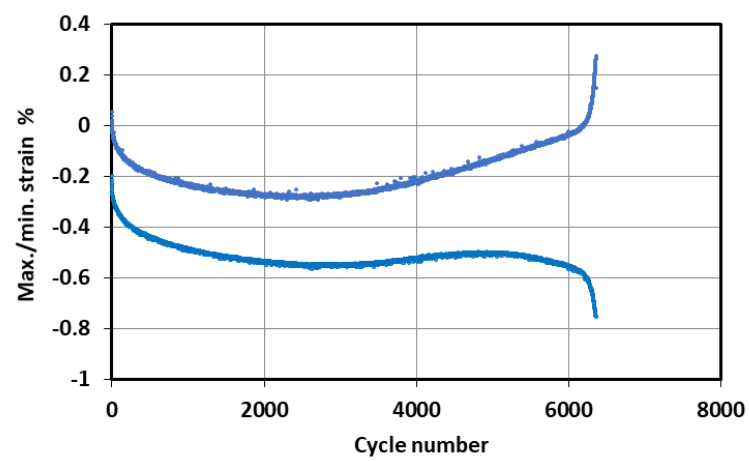

(c)

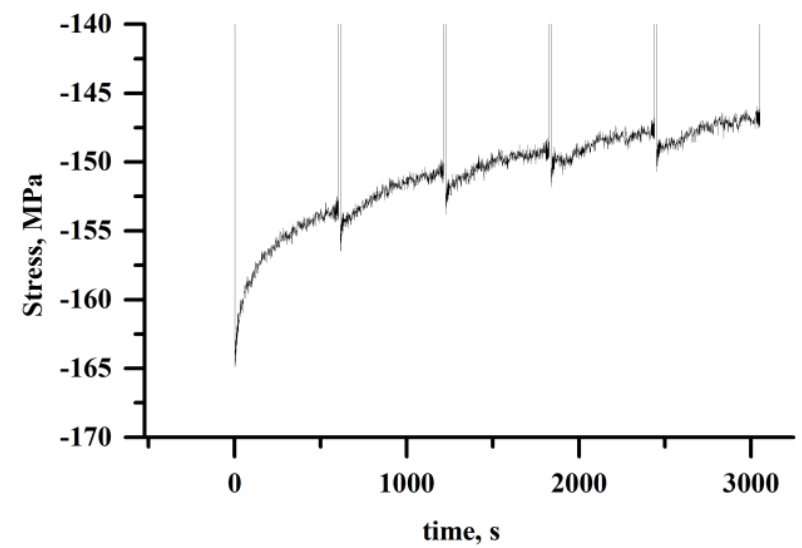

(e)

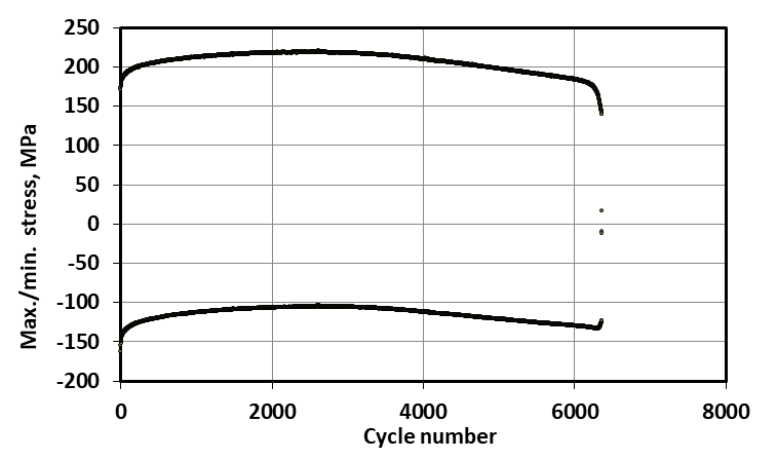

(b)

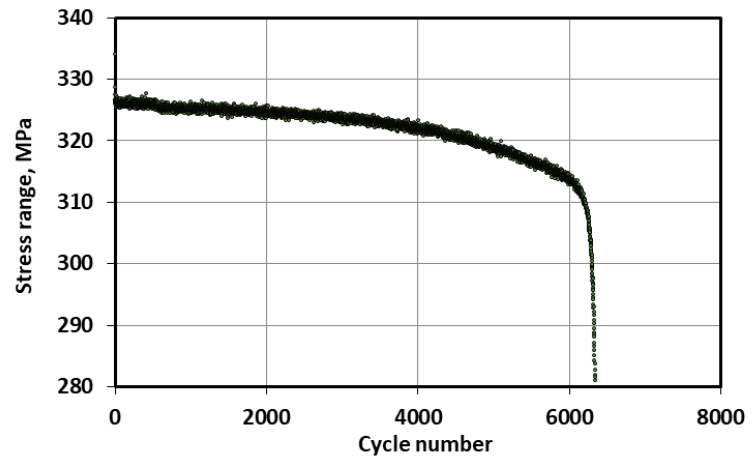

(d)

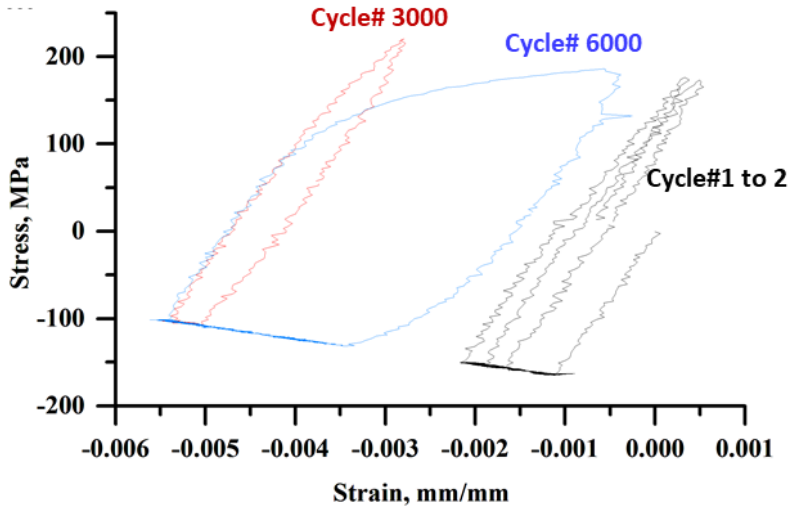

(f)

Fig. 24. Plots of the strain ranges (a), maximum/minimum stresses (b), maximum/minimum strains (c), stress ranges (d), stress history of the first five cycles (e) and representative hysteresis loops (f) for SB11. 


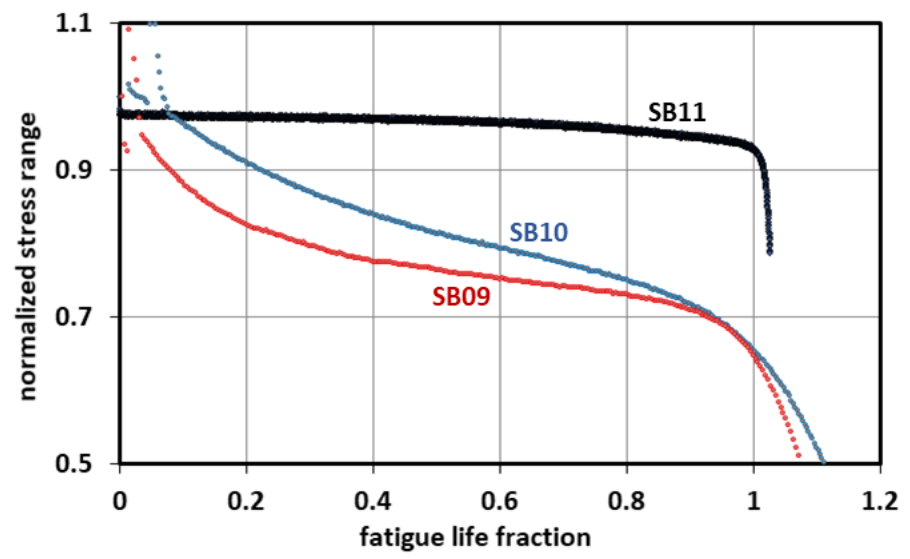

Fig. 25. Comparison of the cyclic softening effect for SBSMT tests on Gr. 91.

\subsection{SUMMARY OF THE SMT RESULTS FOR GR. 91}

All the test results for this report on Gr. 91 (heat 30176) using both TBSMT and SBSMT techniques are summarized in Table 5. Based on these data and the previous discussions of the test results, the following two observations are obvious. First, larger elastic follow-up will shorten the CF life, as shown by comparing TB10, TB08, and TB07. This reduction is due to the retardation of the stress relaxation by the elastic follow-up effect and hence enhanced creep damage during the holding segment. Second, with the same elastic follow-up and holding time, larger applied strain ranges will decrease the cycle life, a similar trend to the standard fatigue or CF.

Table 5. Summary of SMT CF results on Gr. 91 at $650^{\circ} \mathrm{C}$ (heat 30176).

\begin{tabular}{l|c|c|c|c|c}
\hline Test ID & SMT test method & $\begin{array}{c}\text { Elastic follow- } \\
\text { up factor, } \mathbf{Q}\end{array}$ & $\begin{array}{c}\text { Initial stable } \\
\text { strain range, } \%\end{array}$ & Hold time, $\mathbf{s}$ & $\begin{array}{c}\text { Cycles to } \\
\text { failure }\end{array}$ \\
\hline TB03 & $\begin{array}{c}\text { TBSMT with room- } \\
\text { temperature (RT) } \\
\text { driver bar }\end{array}$ & 3.5 & 0.30 & 600 & 2050 \\
\hline TB07 & $\begin{array}{c}\text { TBSMT with RT } \\
\text { driver bar }\end{array}$ & 4.1 & 0.53 & 600 & 750 \\
\hline TB08 & $\begin{array}{c}\text { TBSMT with RT } \\
\text { driver bar }\end{array}$ & 3.5 & 0.55 & 600 & 800 \\
\hline TB06 & $\begin{array}{c}\text { TBSMT with RT } \\
\text { driver bar }\end{array}$ & 4 & 0.90 & 600 & 170 \\
\hline TB10 & $\begin{array}{c}\text { TBSMT with driver } \\
\text { bar at 650 }\end{array}$ & 2.1 to 4.7 & 0.55 & 600 & 480 \\
\hline SB05 & SBSMT & 3.8 & 0.54 & 600 & 680 \\
\hline SB09 & SBSMT & 12 & 0.70 & 600 & 250 \\
\hline SB10 & SBSMT & 12 & 0.62 & 600 & 330 \\
\hline SB11 & SBSMT & 12 & 0.25 & 600 & 6200 \\
\hline
\end{tabular}

The results are also presented in Fig. 26 by plotting the measured initial stable strain range against the cycles to failure for all the test results, regardless of the differences in elastic follow up. In this figure, the average fatigue curve for Gr. 91 at $650^{\circ} \mathrm{C}$ is also plotted. Using the similar concept of generating a design fatigue curve from an average fatigue curve, a reduction factor of factor $2 / 15$ was applied to the average fatigue curve (i.e., factor of 2 for strain range and a factor of 15 for the cycles). The dashed line represents 
the lower bound after applying the $2 / 15$ reduction factor. This $2 / 15$ reduction curve is shown to envelope all the available test data. Of course, the test results are limited, and the hold time is short in these tests, but the concept of using an existing standard fatigue or CF database to generate SMT-based design curves is more practical and economical. SMT CF experiments and analysis will still be required to ensure the bounding elastic follow-up factor to be used for the SMT-based design methodology.

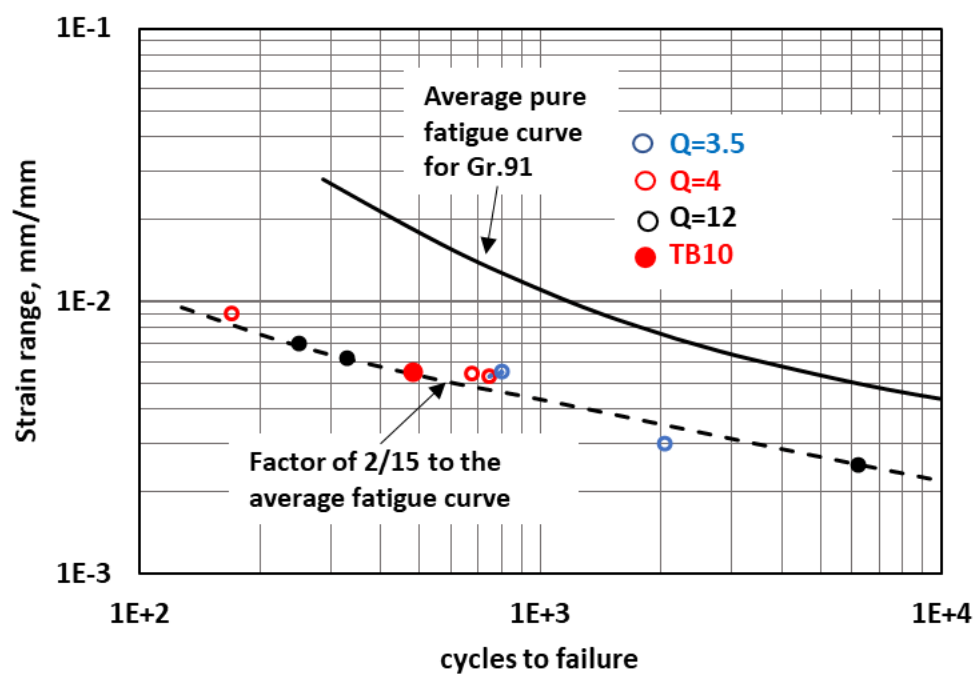

Fig. 26. SMT CF test results on $\mathrm{Gr} .91$ at $650^{\circ} \mathrm{C}$.

\section{SUMMARY}

Four critical tests were performed on Gr. 91 to evaluate the effect of mean stress under strain-controlled fatigue loading. The results show that the mean stresses introduced by the non-zero mean strain could not be maintained under strain-controlled fatigue and resulted in negligible effect on the fatigue life. This study concludes that mean stress correction is not recommended for the fatigue design curves in Division 5 for Gr. 91. Since Gr. 91 exhibits strong cyclic softening, experimental and modeling research are needed to support the extension of the EPP strain limits code cases to Gr. 91. A specially designed experiment was performed on Gr. 91 to provide the critical information to finalize the softening factor for Gr. 91 for EPP analysis and validate the methodology for developing the softening factors.

Testing in support of the development of an integrated EPP plus SMT CF evaluation methodology continued. This integrated SMT-based CF evaluation methodology significantly simplified the CF evaluation procedure and removed the over-conservatism of the existing CF damage diagram method. In this report, the newly improved SMT testing techniques were validated on Gr. 91 by generating SMT CF failure data at different strain ranges and with various elastic follow-ups. The immediate needs for SMT experiments are test results at longer holding times and different temperatures. Modeling analysis is needed to select bounding elastic follow-up factors for the testing. 


\section{REFERENCES}

ASME Boiler and Pressure Vessel Code, Section III Division 5 Subsection HB Subpart B (2019 Edition).

ASME B\&PV Code Case N-861, Satisfaction of Strain Limits for Division 5 Class A Components at Elevated Temperature Service Using Elastic-Perfectly Plastic Analysis.

ASME B\&PV Code Case N-862, Calculation of Creep-Fatigue for Division 5 Class A Components at Elevated Temperature Service Using Elastic-Perfectly Plastic Analysis Section III, Division 5.

JSME Codes for Nuclear Power Generation Facilities - Rules on Design and Construction for Nuclear Power Plants, Part II Fast Reactor Code, JSME S NC2-2016 (2016)

J. R. DiStefano et al., (1985), Summary of Modified 9Cr-1Mo Steel Development Program: 1975-1985, Technical Report No. ORNL-6303, Oak Ridge National Laboratory, Oak Ridge, Tennessee.

Messner, M. C. and Sham, T.-L., (2017), FY17 Status Report on the Initial EPP Finite Element Analysis of Grade 91 Steel, Technical Report No. ANL-ART-94, Argonne National Laboratory, Chicago, IL.

Messner, M. C. and Sham, T.-L. (2018), Initial development and extension of EPP methods to Grade 91, Argonne National Laboratory technical report ANL-ART-133

Messner, M. C. and Sham, T.-L. (2019), Draft ASME Section III Division 5 Code Cases to extend EPP strain limits and creep-fatigue design methods to Grade 91, Argonne National Laboratory technical report ANL-ART-165.

Recommended test procedure for fatigue testing of metallic materials below the creep range REVISION 4 , Prepared by Subgroup on fatigue strength, ASME boiler and pressure vessel committee, The American Society of Mechanical Engineers.

Wang, Y., Sham, T.-L, and Jetter, R. I., (2013), Progress report on the development of test procedure for the two-bar thermal ratcheting experiment for Alloy 617, ORNL/TM-2013/318, Oak Ridge National Laboratory, Oak Ridge, TN.

Wang, Y., Jetter, R. I. and Sham, T.-L, (2014), Application of Combined Sustained and Cyclic Loading Test Results to Alloy 617 Elevated Temperature Design Criteria, ORNL/TM-2014/294, Oak Ridge National Laboratory, Oak Ridge, TN.

Wang, Y., Jetter, R. I., Baird, S. T., Pu, C. and Sham, T.-L., (2015), Report on FY15 Two-Bar Thermal Ratcheting Test Results, ORNL/TM-2015/284, Oak Ridge National Laboratory, Oak Ridge, TN.

Wang, Y., Jetter, R. I., and Sham, T.-L., (2016a), FY16 Progress Report on Test Results In Support Of Integrated EPP and SMT Design Methods Development, ORNL/TM-2016/330, Oak Ridge National Laboratory, Oak Ridge, TN.

Wang, Y., Jetter, R. I., and Sham, T.-L., (2016b), Preliminary Test Results in Support of Integrated EPP and SMT Design Methods Development, ORNL/TM-2016/76, Oak Ridge National Laboratory, Oak Ridge, TN. 
Wang, Y., Messner and Sham, T.-L., (2017a), FY17 Status Report on Testing Supporting the Inclusion of Grade 91 Steel as an Acceptable Material for Application of the EPP Methodology, ORNL/TM2017/388, Oak Ridge National Laboratory, Oak Ridge, TN.

Wang, Y., Jetter, R. I., Messner, M., Mohanty, S., and Sham, T.-L., (2017b), Combined Load and Displacement Controlled Testing to Support Development of Simplified Component Design Rules for Elevated Temperature Service, Proceedings of the ASME 2017 Pressure Vessels and Piping Conference, PVP2017-65455.

Wang, Y., Jetter, R. I., Messner, M., and Sham, T.-L., (2018a), Report on FY18 Testing Results in Support of Integrated EPP-SMT Design Methods Development, ORNL/TM-2018/887, Oak Ridge National Laboratory, Oak Ridge, TN.

Wang, Y., Messner, M., and Sham, T.-L., (2018b), Report on the FY18 Uniaxial Material Model Testing and Key Feature Test Articles Testing of Grade 91, ORNL/TM-2018/885, Oak Ridge National Laboratory, Oak Ridge, TN.

Wang, Y., Jetter, R. I., Messner, M., and Sham, T.-L., (2019a), Development of Simplified Model Test Method for Creep-fatigue Evaluation, Proceedings of the ASME 2019 Pressure Vessels and Piping Conference, PVP2019-93648, July 2019, San Antonio, TX, USA.

Wang, Y., Jetter, R. I., Messner, M., and Sham, T.-L., (2019b), Report on FY19 Testing in Support of Integrated EPP-SMT Design Methods Development, ORNL/TM-2019/1224, Oak Ridge National Laboratory, Oak Ridge, TN. 